\title{
Clinical management for other iatrogenic immunodeficiency-associated lymphoproliferative disorders
}

\author{
Michihide Tokuhira, ${ }^{1)}$ Jun-ichi Tamaru, ${ }^{2)}$ and Masahiro Kizaki ${ }^{1)}$
}

Other iatrogenic immunodeficiency-associated lymphoproliferative disorders (OIIA-LPD), a category of immunodeficiencyassociated LPD according to the World Health Organization classification, is associated with immunosuppressive drugs (ISDs). Several factors, including autoimmune disease (AID) activity, Epstein-Barr virus (EBV) infection, ISD usage, and aging, influence the development of OIIA-LPD, resulting in complicated clinical courses and outcomes. Most OIIA-LPD develops in patients with rheumatoid arthritis using methotrexate (MTX-LPD). The management of MTX-LPD is based on the clinical course, i.e., with/without regression, with/without relapse/regrowth event (RRE), LPD subtype, and ISDs for AIDs after LPD development. There are three clinical courses after ISD withdrawal: regressive LPD without relapse/regrowth (R-G), regressive LPD with RRE (R/R-G), and persistent LPD (P-G). The majority of EBV+ diffuse large B-cell lymphomas are classified in R-G, whereas classic Hodgkin lymphoma is generally classified in R/R-G. Polymorphic LPD (P-LPD) in MTX-LPD develops with heterogeneous pathological features similar to monomorphic LPD. Chemotherapy for MTX-LPD is selected according to that for de novo LPD, although the strategy for aggressive P-LPD and non-specific LPD is not well established. The absolute lymphocyte count in the peripheral blood has been suggested as a candidate marker for MTX-LPD development and RRE. Several clinical issues, including correct diagnosis among overlapping clinicopathological features in MTX-LPD and clinical management of LPD by ISDs other than MTX, require further investigation.

Keywords: clinical management, iatrogenic immunodeficiency-associated lymphoproliferative disorders, methotrexate, rheumatoid arthritis

\section{OTHER IATROGENIC IMMUNODEFICIENCY- ASSOCIATED LYMPHOPROLIFERATIVE DISORDERS (OIIA-LPD)}

Immune deficiency is an important factor in the pathogenesis of LPD among a number of influencing events. According to the World Health Organization (WHO) classification, immunodeficiency-associated LPD (IA-LPD) is classified into four subtypes; LPD associated with primary immune disorders, lymphomas associated with HIV infection, post-transplant LPD (PTLD), and OIIA-LPD. ${ }^{1,2}$ OIIALPD is defined as lymphoid proliferations or lymphomas that develop in patients receiving immunosuppressive drugs (ISDs) for autoimmune diseases (AIDs) or conditions other than the post-transplant setting in the 2008 WHO classification. ${ }^{1}$ However, the ISD-mediated LPD category remains controversial because of the difficulty in confirming a direct effect of ISDs based on the high risk of LPD development in patients with AIDs as a natural clinical course. The standardized incidence ratio (SIR) of rheumatoid arthritis (RA) is 2-20-fold that in the control healthy population. ${ }^{3-12}$ In particular, the incidence rate is high in Japan. For example, the SIR in the NinJa study, ${ }^{6}$ SUCURE study, ${ }^{8}$ and IORRA cohort ${ }^{10}$ in Japan was 3.43, 6.18, and 4.61, respectively. In addition, the disease severity and accumulated inflammatory activity of RA may be related to LPD development. ${ }^{13}$ Although different AIDs are treated using different ISDs in OIIA-LPD, there is no direct evidence of the pathogenesis of LPD, except for LPD regression after ISD withdrawal. Methotrexate (MTX) is recognized as the ISD associated with LPD in the WHO classification (2001), ${ }^{14}$ categorized as the MTX-LPD disease entity. The category of OIIA-LPD was defined in the 2008 and 2017 WHO classifications ${ }^{1,2}$ to replace the concept of MTX-LPD. Among ISDs, MTX and anti-tumor necrosis factor inhibitors (TNFi) are candidates initiating LPD. ${ }^{1,2}$

\footnotetext{
Received: February 19, 2019. Revised: March 18, 2019. Accepted: March 26, 2019. Onlune Published: June 28, 2019

DOI:10.3960/jslrt.19007

${ }^{1}$ Department of Hematology, Saitama Medical Center, Saitama Medical University, Kawagoe, Saitama, Japan, ${ }^{2}$ Department of Pathology, Saitama Medical Center, Saitama Medical University, Kawagoe, Saitama, Japan

Corresponding author: Michihide Tokuhira, Department of Hematology, Saitama Medical Center, Saitama Medical University, 1981 Kamoda, Kawagoe, Saitama 350-8550, Japan.

E-mail: tokuhira@saitama-med.ac.jp

Copyright (C) 2019 The Japanese Society for Lymphoreticular Tissue Research

(cc) BY-NC-SA This work is licensed under a Creative Commons Attribution-NonCommercial-ShareAlike 4.0 International License.
} 
OIIA-LPD originates from many cell types, including B, $\mathrm{T}$, and natural killer (NK) cells..$^{1,2,14}$ The major types of monomorphic LPD (M-LPD) are diffuse large B cell lymphoma (DLBCL) and classic Hodgkin lymphoma (CHL), comprising $58 \%$ and $15.3 \%$ of 274 cases of OIIA-LPD, respectively, in the $2017 \mathrm{WHO}$ classification. ${ }^{1}$ Rare subtypes of LPD include polymorphic features, such as polymorphic/lymphoplasmacytic infiltrates (P/L-I), Hodgkin-like lesions (HLL), and Epstein-Barr virus-positive mucocutaneous ulcer (EBVMCU), which comprise 9.9\%, 2.2\%, and $3.3 \%$, respectively. ${ }^{1}$ Although non-destructive LPD (ND-LPD), defined as PTLD in the WHO classification, ${ }^{1,2}$ is not described in OIIA-LPD, it accounts for 10-15\% of MTXLPD according to previous reports. ${ }^{15,16}$ Although ISDs other than MTX promote LPD development based on previous reports, assessment of such non-MTX-LPD is difficult because of the small number of cases. Thus, this article focuses on the management of MTX-LPD in OIIA-LPD. In addition, although the WHO classification does not separate DLBCL subtypes, such as EBV+DLBCL and DLBCL-NOS, in OIIA-LPD, ${ }^{1,2}$ we analyzed them specifically focusing on the differences between de novo DLBCL and MTX-DLBCL.

\section{LPD REGRESSION AFTER ISD WITHDRAWAL}

LPD regression after ISD withdrawal is one of the unique characteristics, suggesting a direct influence on the pathogenesis of LPD development. Although this phenomenon is also described in other disorders like PTLD, ${ }^{17}$ it mainly develops in patients with MTX-LPD. LPD regression after MTX withdrawal is observed in $20-70 \%$ of patients. In the 2017 WHO classification, $40.4 \%$ of 188 patients with OIIALPD demonstrated LPD regression. ${ }^{1}$ Among 545 patients with MTX-LPD collected in a study by Pfizer, Japan, LPD regression after MTX withdrawal comprised $86.2 \%$ of the 302 evaluable events. ${ }^{18}$ As more than $50 \%$ of the patients without relapse/regrowth events (RRE) after LPD regression do not require additional chemotherapy and have a superior overall survival (OS), ${ }^{16,19}$ watchful wait therapy (WW) is recommended initially when MTX-LPD develops. To clarify the clinical management of MTX-LPD, which includes avoiding additional therapy for regressive LPD, we propose three clinical courses after ISD withdrawal: LPD regression after ISD withdrawal without RRE (regressive group, R-G), LPD regression after ISD withdrawal with RRE (relapse/ regrowth group, R/R-G), and persistent LPD after ISD withdrawal (persistent group, P-G) (Figure 1). ${ }^{16,19}$ In these reports, the ratio of the three groups was similar. In $\mathrm{R}-\mathrm{G}$ and $\mathrm{R} / \mathrm{R}-\mathrm{G}$, but not P-G, the direct influence of ISDs on the pathogenesis of LPD development was suggested because they exhibited LPD regression phenomenon. In $\mathrm{P}-\mathrm{G}$, de novo LDP and irreversible MTX-LPD due to ISDs are involved, although it is difficult to discriminate between them. Regarding this point, the differences between de novo LPD and MTX-LPD have been investigated in several studies. ${ }^{20-23}$ Carreras et al. demonstrated differences in the phenotype and genetic characteristics of MTX-LPD-DLBCL and de novo DLBCL such as a genomic profile with $3 \mathrm{q}$ and 12 gains, $13 \mathrm{q}$ loss, different expression levels of relevant pathogenic biomarkers, and a microenvironment with high numbers of cytotoxic T lymphocytes and M2 macrophages. ${ }^{21}$ In other studies, most MTX-DLBCL cases had an activated-Bcell immunophenotype, especially Epstein-Barr virus (EBV) - positive cases, and MTX-EBV+DLBCL commonly expressed CD30. ${ }^{22,23}$ Ejima-Yamada et al. found that EBV infection in MTX-B cell-LPD in patients with RA is associated with a lower incidence of $\mathrm{CpG}$ island methylator phenotype and B-cell lymphoma 2 expression, resulting in LPD regression after MTX withdrawal and improved prognoses. ${ }^{24}$

The three clinical groups have different trends in clinical parameters: serum C-reactive protein (CRP) and serum soluble interleukin-2 receptor (sIL-2R) are increased in $\mathrm{R} / \mathrm{R}-\mathrm{G}$, whereas serum lactate dehydrogenase (LDH), CRP, and sIL$2 \mathrm{R}$ are increased in P-G. ${ }^{16,19}$ Furthermore, the OS for R-G is significantly better than that for the other two groups. ${ }^{16}$ Thus, RRE is an important event among patients with regressive LPD after ISD withdrawal. According to previous reports, RRE develops within 2-3 years after LPD regression. ${ }^{15,16,19,25}$ In our study, the rate of regressive LPD (R-G and R/R-G) was different for each LPD of MTX-LPD; a higher rate was observed for MTX-EBV+DLBCL, MTX-PLPD, MTX-EBVMCU and MTX-ND-LPD, whereas MTXDLBCL-NOS had a lower rate.

Recent studies have suggested that lymphocytes play an important role in the pathogenesis of LPD regression after ISD. ${ }^{26-30}$ Inui et al. reported recovery of lymphocytes in peripheral blood (PB) in patients with regressive LPD after MTX, although not in patients with P-G. ${ }^{26}$ Saito et al.

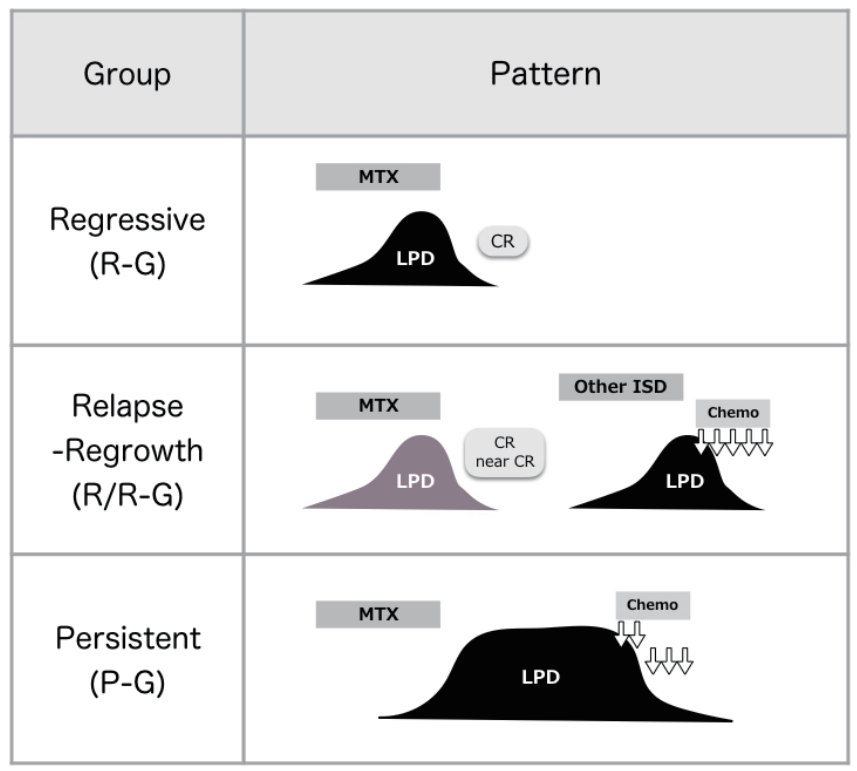

Fig. 1. Three clinical courses of methotrexate-associated lymphoproliferative disorders (MTX-LPD) ${ }^{19}$

Three clinical courses are observed in patients with MTX-LPD after immunosuppressive drug (ISD) withdrawal: regressive LPD without relapse/regrowth event (RRE, regressive group, R-G), regressive LPD with RRE (R/R-G), and persistent LPD (P-G). CR, complete response; Chemo, chemotherapy. 
confirmed this finding among patients with MTX-LPD, and reported that the recovered lymphocytes were composed of CD8+ T cells and natural killer (NK) cells. ${ }^{27}$ They also demonstrated a decrease in the absolute lymphocyte count (ALC) in PB towards the time of LPD development in patients with regressive LPD, suggesting a key role of lymphocytes in the pathogenesis of MTX-LPD. ${ }^{27}$ Furthermore, the change in lymphocytes may influence RRE. Among 43 patients with MTX-LPD, the ALC gradually decreased toward RRE in R/ R-G, but not in R-G. ${ }^{30}$ Regarding prognosis factors, an ALC of $<600 / \mu \mathrm{L}$ in $\mathrm{PB}$ is one of the prognostic factors for de novo CHL. ${ }^{31}$ The value of ALC as a prognostic factor has also been confirmed for several lymphomas. ${ }^{32-35}$ Taken together, lymphocytes in PB are suggested to be one of the triggers in the development of MTX-LPD.

\section{CLINICAL MANAGEMENT OF MTX-LPD}

The clinical management of MTX-LPD is illustrated in Figure 2, according to the previous reports in clinical practice. After WW following cessation of ISDs, patients without RRE do not require additional therapy (R-G, [1]), whereas additional chemotherapy is administered at the time of RRE (R/R-G, [2]). Chemotherapy is also considered for patients with non-regressive LPD under WW (P-G, [3]). On the other hand, the evaluation of $\mathrm{WW}$ has been considered for OIIA-LPD since around 2010, and it is not suitable for patients with aggressive LPD with severe organ damage. Thus, chemotherapy is initiated without confirmation of the regressive phase under these conditions (chemotherapy

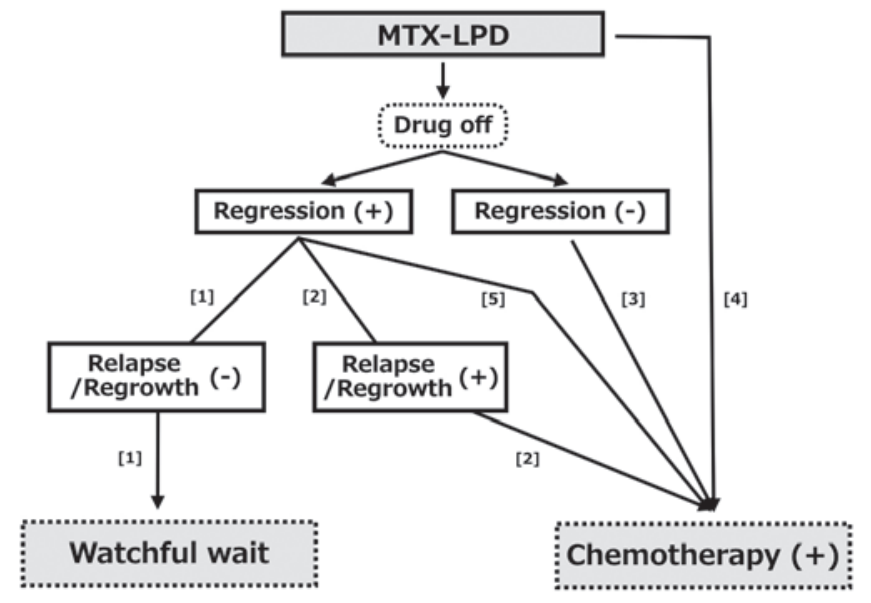

Fig. 2. Clinical management of methotrexate-associated lymphoproliferative disorders (MTX-LPD)

The first step after MTX-LPD development is watchful waiting (WW) following the cessation of immunosuppressive drugs (ISDs). Additional therapy is not required for patients without relapse/ regrowth event (RRE, R-G, [1]), but chemotherapy is administered when RRE develops (R/R-G, [2]). Chemotherapy is also considered for patients with non-regressive LPD under WW (persistent group, $\mathrm{P}-\mathrm{G},[3])$. On the other hand, WW therapy is not suitable for patients with aggressive LPD, and chemotherapy is initiated without confirmation of the regressive phase (chemotherapy group, $\mathrm{Ch}-\mathrm{G}$, [4]). Furthermore, chemotherapy is initiated if the LPD remains in partial response or exhibits a low response during regression (included in P-G, [5]). The details are also described in the text. group, Ch-G, [4]). Furthermore, chemotherapy is initiated if the LPD has an inadequate response under LPD regression (included in P-G, [5]). Based on reports of M-LPD in MTXLPD, including DLBCL and CHL, chemotherapy is selected according to the strategy of de novo LPD. In contrast, little information is available about patients with aggressive polymorphic LPD (P-LPD), such as P/L-I, HLL, and EBVMCU, in MTX-LPD. Based on previous reports, chemotherapy for P-LPD is selected according to the similar pathological features to DLBCL or CHL, as described in later reports of MTX-P-LPD and MTX- EBVMCU. Although the clinical outcome of patients with ND-LPD is as good as that of patients with P-LPD, aggressive ND-LPD is observed. ${ }^{15,16}$ Similar to P-LPD, chemotherapy for such aggressive cases is based on the diagnosis of similar pathological features in M-LPD (described in the MTX-ND-LPD section). However, the relevance of this concept of aggressive LPD in P-LPD and ND-LPD has yet to be evaluated.

Regarding the administration of ISDs at the time of LPD development, all ISDs are basically withdrawn because identifying the drug responsible for LPD is difficult. The majority of OIIA-LPD is MTX-LPD in RA. Although LPD associated with ISDs, except MTX (non-MTX-LPD), may develop, our understanding of non-MTX-LPD is limited because of the small number of patients with combinations of AIDs and ISDs. In addition, the history of MTX administration is carefully assessed among non-MTX-LPD patients because RRE occurs within several years after the withdrawal of MTX. In this article, the clinical features of MTX-LPD are listed based on data summarized from previous reports that described the clinical information such as the clinical patterns of R-G, R/R-G, P-G, and Ch-G.

\section{$M T X-D L B C L$}

The common LPD in OIIA-LPD is DLBCL (30-60\%). According to the WHO classification, DLBCL comprises several subtypes, including not-otherwise-specified (NOS) and $\mathrm{EBV}$ positive $(\mathrm{EBV}+)$ subtypes. ${ }^{1}$ In this article, we analyzed the clinical features of MTX-DLBCL, including subtypes such as MTX-EBV+ DLBCL and MTX-DLBCL-NOS, and highlighted the clinical aspects in Tables 1 and 2. ${ }^{16,25,36-55}$ Although the WHO classification described DLBCL as DLBCL-type including DLBCL and LPDs similar to the pathological features of DLBCL in OIIA, ${ }^{25}$ in our study demonstrated DLBCLs as MTX-EBV+ DLBCL and MTXDLBCL-NOS. The number of patients with MTXEBV+DLBCL and MTX-DLBCL-NOS were 66 and 50, respectively (Tables 2,3 ). Thus, the rate of EBV positivity was $57 \%$ among patients with MTX-DLBCL, although this value varies in previous studies. For example, EBV positivity in $24.1 \%$ of 29 patients, ${ }^{56} 45 \%$ of 42 patients, ${ }^{57}$ and $82 \%$ of 34 patients ${ }^{25}$ was reported. The incidence of de novo $\mathrm{EBV}+\mathrm{DLBCL}$ among all the DLBCL cases was $<5-15 \%$ of Asian and Latin American patients and $<5 \%$ of Western patients. ${ }^{1,2}$ Thus, the rate of EBV positivity is higher in MTX-DLBCL. Although MTX-EBV+DLBCL is female dominant (71\%), MTX-DLBCL-NOS has a lower incidence 


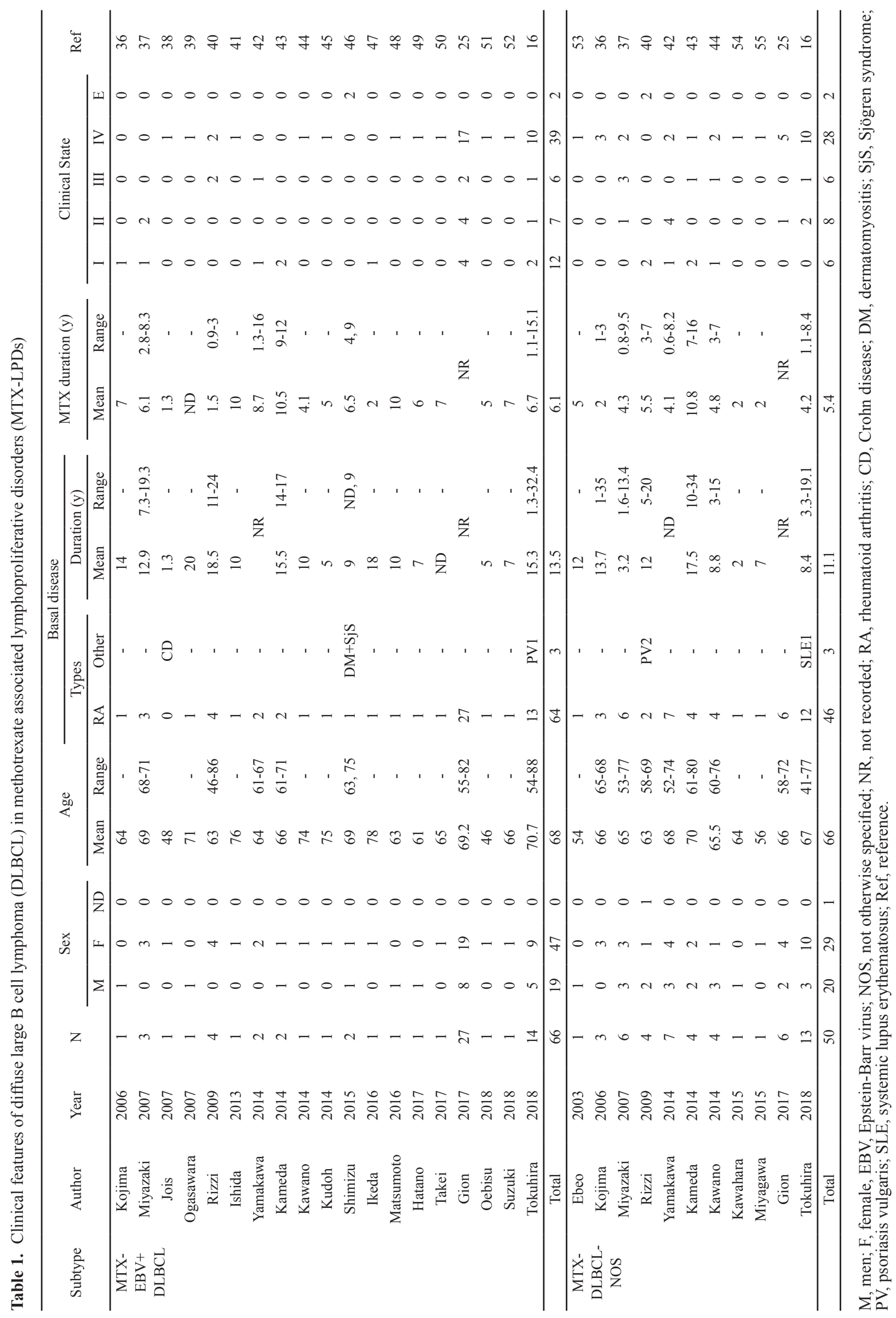




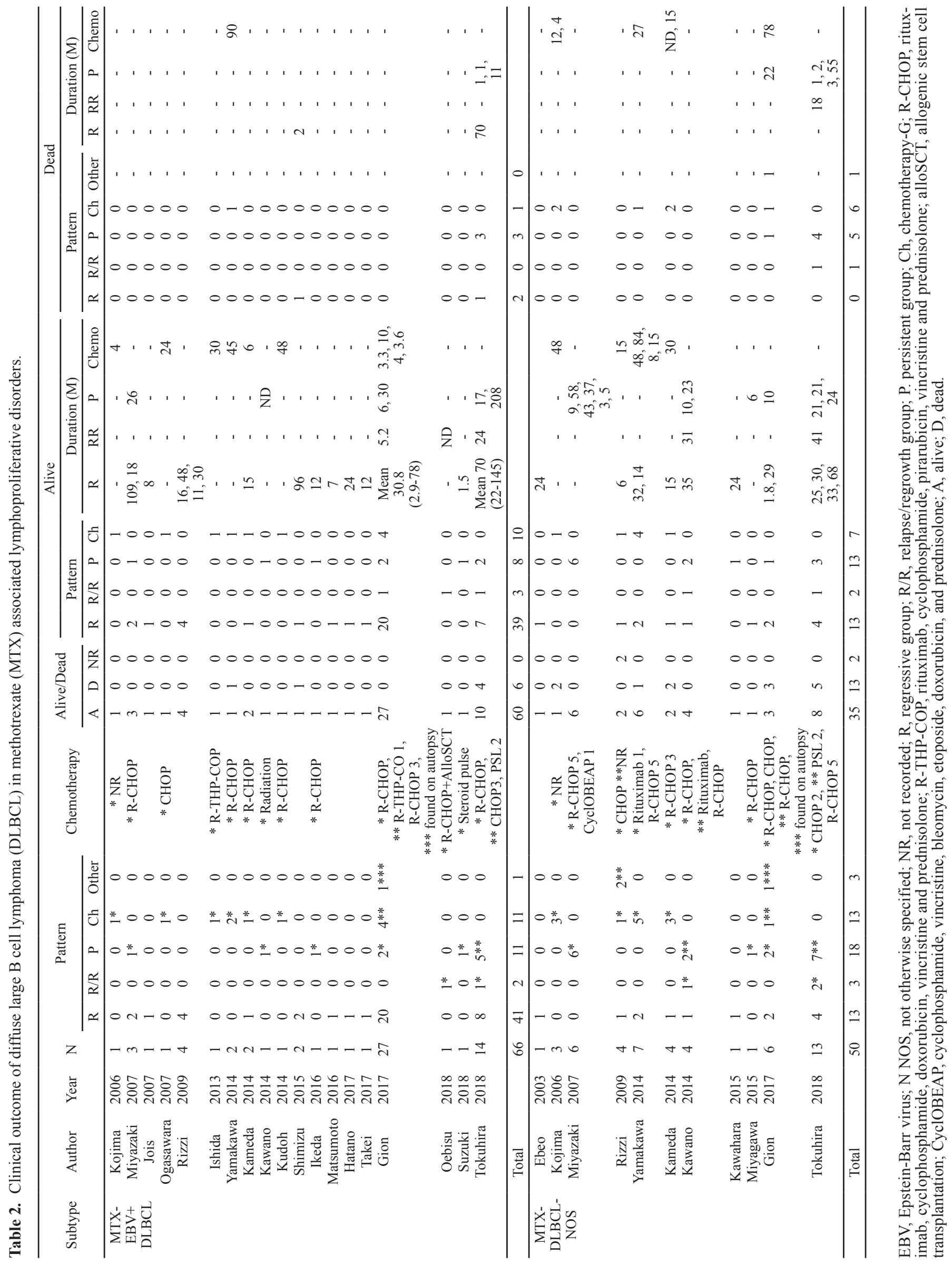




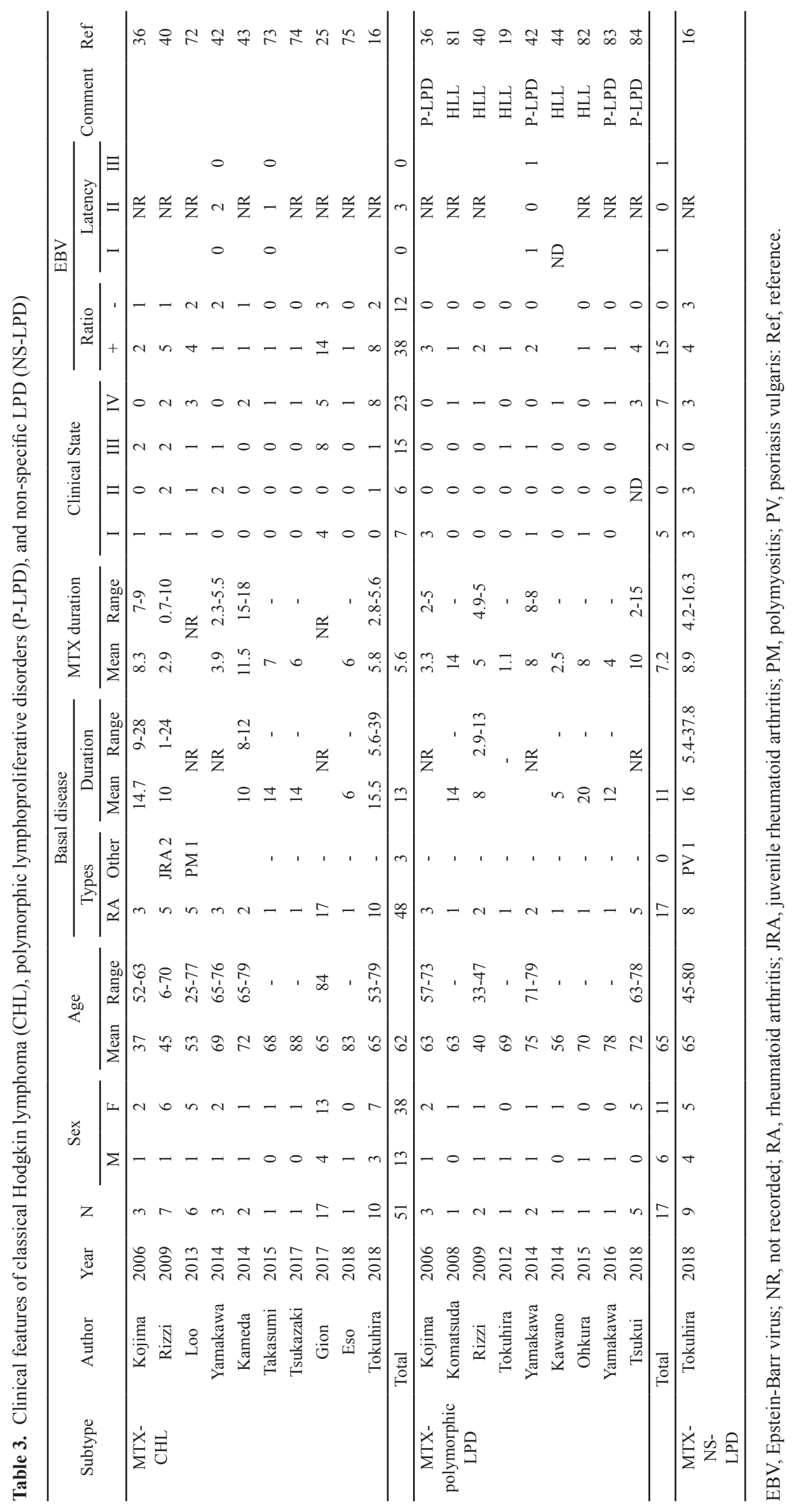


rate in females $(59 \%)$. Mean ages at the development of MTX-DLBCL are similar between MTX-EBV+DLBCL and MTX-DLBCL-NOS (66 and 68 years, respectively, Table 1), which is similar to de novo DLBCL. ${ }^{58}$ In both types of MTX-DLBCL, the most common AID was RA, and the duration of AID and MTX administration was over 10 and 5 years, respectively. Two-thirds of the patients had clinical stage (CS) 3 or 4 MTX-DLBCL (Table 1). Regarding the laboratory data for MTX-DLBCL in our previous study, ${ }^{16}$ the median serum levels of LDH, CRP, and sIL-2R in $\mathrm{EBV}+\mathrm{DLBCL}$ and DLBCL-NOS were $240 \mathrm{IU} / \mathrm{L}, 1.4 \mathrm{mg} / \mathrm{dL}$, $1440 \mathrm{U} / \mathrm{mL}$, and $208 \mathrm{IU} / \mathrm{L}, 4.7 \mathrm{mg} / \mathrm{dL}$, and $1525 \mathrm{U} / \mathrm{mL}$, respectively, demonstrating similar trends between the two types of MTX-DLBCL. The EBV latency in MTX$\mathrm{EBV}+\mathrm{DLBCL}$ was type II dominant. ${ }^{58}$

The clinical outcomes of MTX-DLBCL are listed in Table 2. The ratios of R-G, R/R-G, P-G, and Ch-G in MTXEBV+DLBCL and MTX-DLBCL-NOS were $62 \%, 3 \%, 17 \%$, $17 \%$, and $26 \%, 6 \%, 36 \%, 26 \%$, respectively. The rate of regressive LPD (R-G+R/R-G) was higher in MTXEBV+DLBCL than in MTX-DLBCL-NOS (65\% and $32 \%$, respectively), supporting the previous report..$^{58}$ The ratio of patients with RRE in MTX-EBV+DLBCL and MTXDLBCL-NOS was low ( $4 \%$ and $6 \%$, respectively). The survival rate was higher for MTX-EBV+DLBCL than for MTXDLBCL-NOS (91\% and 60\%, respectively) (Table 2). In addition, poorer survival rates were noted for $\mathrm{P}-\mathrm{G}$ and $\mathrm{Ch}-\mathrm{G}$ of MTX-DLBCL-NOS ( $72 \%$ and $53 \%$, respectively), whereas higher survival rates were found for R-G of MTXEBV+DLBCL and MTX-DLBCL-NOS $(95 \%$ and $100 \%$, respectively). As de novo EBV+DLBCL in elderly patients has a poor prognosis ${ }^{59-61}$ the clinical outcome of MTX$\mathrm{EBV}+\mathrm{DLBCL}$ reflects a superior OS. Regarding the pathological heterogeneity of OIIA-LPD, LPD resembling DLBCL includes P-LPD, such as EBVMCU, P/L-I, and HLL. ${ }^{1}$ Furthermore, the definition of EBVMCU includes the clinical manifestations, such as ulceration with EBV-positive cells, whereas P-LPD has similar pathological features to EBVMCU without the clinical manifestation of skin or mucosal ulceration. In addition, the OS for P-LPD was as good as that for EBVMCU. Thus, discriminative clinicopathological diagnosis of EBV+LPD, including EBV+DLBCL, P-LPD, and EBVMCU, in OIIA-LPD remains vague. Previous reports found a similar OS between MTX-EBV+DLBCL and MTX-DLBCL-NOS. ${ }^{16,57}$ In our series, several patients with MTX-EBV+DLBCL or MTX-DLBCL-NOS in P-G died due to progressive disease. ${ }^{16}$ Due to the delay of diagnosis of MTX-DLBCL when the disease entity of MTX-LPD was not well recognized, insufficient chemotherapy, such as prednisolone monotherapy, was consequently given to the patients, resulting in poor outcomes. Therefore, withdrawal of ISDs should be first performed to prevent LPD aggravation when manifestations resembling MTX-LPD, such as fever, lymphoadenopathy, or respiratory symptoms, and laboratory abnormalities, such as increased serum LDH, CRP, and sIL-2R, develop (described in "Clinical-MTX-LPD"). The standard therapy for MTX-DLBCL patients with $\mathrm{P}-\mathrm{G}$ or $\mathrm{Ch}-\mathrm{G}$ is R-CHOP-based chemotherapy (Table 2). Rituximab monotherapy is occasionally given to MTX-DLBCL patients considering the LPD and AID activity in clinical practice. ${ }^{44,62}$ Although rituximab monotherapy can be effective against AIDs, especially RA, it is not suitable to cure DLBCL. Other MTX-DLBCL cases are also reported. . $^{2456-59,63-71}$

\section{MTX-CHL}

Fifty-one cases of MTX-CHL from 11 reports are summarized in Tables 3 and 4. 16,25,36,40,42,43,72-75 Although one study described the pathological diagnosis as CHL-type, ${ }^{25}$ such cases were categorized into MTX-CHL in this article. Thirty-eight of the patients were female, and the mean age was 62 years, which is older than that for de novo CHL. ${ }^{58}$ Ninety-four percent of patients (48/51) had RA or other AIDs, such as juvenile RA (JRA, N=1), and polymyositis $(\mathrm{PM}, \mathrm{N}=1)$. The mean duration of AID and MTX administration was 13 years and 5.6 years, respectively. The rate of CS 3 and 4 was $75 \%(41 / 55)$. EBV positivity was noted in $76 \%$ (38/51). Among patients with MTX-CHL in our series, the median serum LDH, CRP, and sIL-2R levels were 214 IU/L, $12.3 \mathrm{mg} / \mathrm{dL}$, and $3110 \mathrm{U} / \mathrm{mL}$, respectively. ${ }^{16}$ The CRP level was significantly higher in CHL than in DLBCL. ${ }^{16}$ Clinical outcomes of MTX-CHL are shown in Table 4. The incidence rates of R-G, R/R-G, P-G, and Ch-G were $14 \%$, $40 \%, 24 \%$, and $21 \%$, respectively. A lower incidence rate of R-G (14\%) and a higher rate of R/R-G (40\%) were noted for MTX-CHL than for DLBCL, suggesting frequent RRE in MTX-CHL. Chemotherapy was administered to $86 \%$ of patients with MTX-CHL (Table 4). Kuita et al. compared 26 patients with MTX-CHL among 219 patients with MTXLPD, and all of them received chemotherapy with a median progression-free survival of 5 months. ${ }^{15}$ Chemotherapy was based on ABVD, although R-CHOP was also given (Table 4). Regarding OS, 78\% of MTX-CHL patients (39/50) survived, although the survival rate differs among studies. For example, MTX-CHL patients in our series with a relatively long observation period (median, 4.4 years) had a poorer OS (5-year OS, 33\%) ${ }^{16}$ than those in other studies. ${ }^{15,25}$ The survival rate in R-G, R/R-G, P-G, and Ch-G was $100 \%, 65 \%$, $67 \%$, and $100 \%$, respectively (Table 4 ). As the observation duration of 4 MTX-CHL patients in R-G was shorter than 2 years, the ratio in R-G may further decrease during the longfollow up. The pathological features of P-LPD, including HLL and EBVMCU, often resemble those of CHL, with Reed-Sternberg-like cells, explaining the difficulty in diagnosis of MTX-CHL. In contrast, the lower rate of R-G in MTX-CHL may be because P-LPD cases are not categorized as MTX-CHL.

Regarding the clinical management, the OS is poorer for MTX-CHL patients in R/R-G $(65 \%)$ than those in Ch-G $(100 \%)$ (Table 4). If RRE occurs at a higher rate in MTXCHL, as found in this analysis, chemotherapy without WW or during WW is one of the options to improve OS, but such a strategy may be less advantageous for patients in R-G $(14 \%)$. Several studies have investigated predictive surrogate 


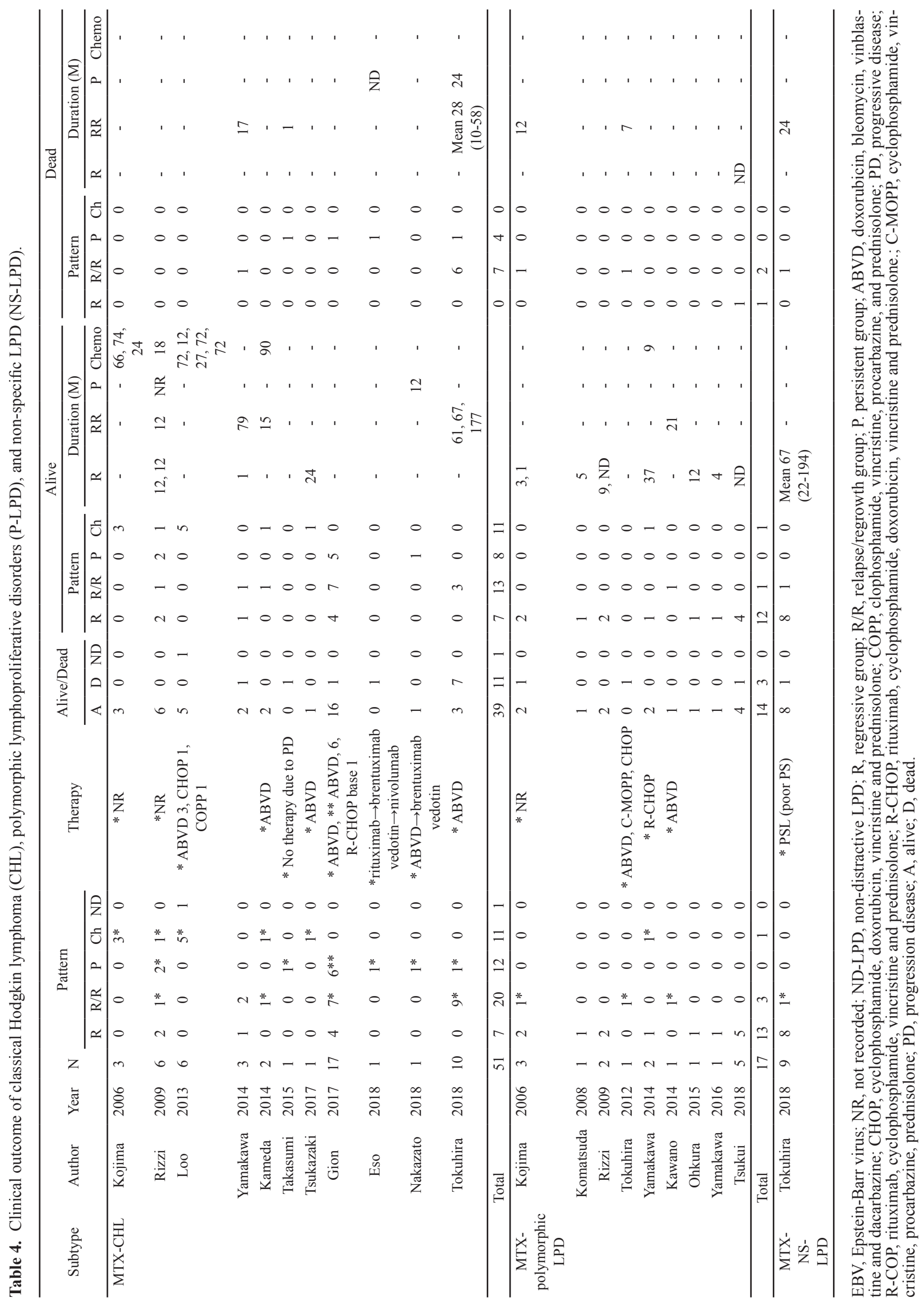


markers for RRE; one such marker is decreased ACL in PB at the time of LPD development or RRE, as mentioned for LPD regression. ${ }^{26-29}$ In our report, an ALC $<1000 / \mu \mathrm{L}$ at the time of LPD development is predictive of RRE..$^{30}$ Regarding other therapy options, several drugs, such as anti-PD-1 antibody and anti-CD30 antibody, can be applied for de novo CHL. ${ }^{75,76}$ Eso et al. described a MTX-CHL patient with oral ulceration receiving rituximab, brentuximab vedotin (BV), and nivolumab during the clinical course. ${ }^{75}$ The response was insufficient and the patient died due to disease progression. In another case report, Nakazato et al. reported a patient with RA-MTX-CHL who relapsed after ABVD administration, and she achieved complete response $(\mathrm{CR})$ and remission of RA by BV administration as salvage therapy. ${ }^{76}$ Other cases of MTX-CHL have been previously reported. ${ }^{37,44,57,65,66,77-79}$ Rizz et al. ${ }^{40}$ and Miranda et al. ${ }^{80}$ also reviewed cases of CHL in OIIA-LPD.

\section{MTX-P-LPD}

B-LPD among IA-LPD usually exhibits EBV-related lesions, including hyperplasia, P-LPD, aggressive lymphomas, and rarely, indolent lymphomas. ${ }^{1}$ The subtypes of PTLD, commonly EBV-mediated, are categorized into 3 types: ND-LPD, P-LPD, and M-LPD. ${ }^{1}$ Although the former 2 subtypes are not clearly defined in OIIA-LPD, the subtypes of polymorphic/lymphoplasmacytic-LPD (the 2008 WHO

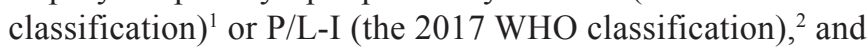
HLL have consistent features with P-LPD. ${ }^{1}$ To clarify this issue in OIIA-LPD, Kurita et al. proposed 3 categories of OIIA-LPD as defined for PTLD: reactive hyperplasia LPD (RH-LPD) as ND-LPD, P-LPD, and M-LPD. ${ }^{15}$ In their analysis, P-LPD, consisting of P/L-I, HLL, and other p-LPD, accounted for $15 \%$ of 219 patients with MTX-LPD. The clinical data for P-MTX-LPD based on the previous reports are shown in Tables 3 and 4. ${ }^{19,36,40,42,44,81-84}$ Among 17 patients with MTX-P-LPD, 11 and 6 were consistent with P-LPD and HLL, respectively. There were six male and 11 female patients. The mean age was 65 years, and all patients had RA. The mean duration of RA and MTX was 11 years and 7.2 years, respectively. Regarding tumor involvement, $41 \%$ of the patients had extranodal lesions, whereas $29 \%$ had localized lesions (Table 3). EBV positivity, based on EBER-1 staining, was $100 \%$ among 14 patients with P-LPD for whom EBER-1 staining was performed. Thirteen of the 17 MTX-P-LPD patients (76\%) were in R-G, whereas 3 patients and 1 patient were in R/R-G and Ch-G, respectively (Table 4). Patients in R/R-G and Ch-G received ABVD and R-CHOP, respectively. The survival rate of the 17 patients with MTX-P-LPD was $82.3 \%$ (14/17). Among the patients with MTX-P-LPD, the patients with ulceration or localized mucosal lesions were categorized into EBVMCU, although the diagnosis was based on the original article in this list. The recommended chemotherapy for aggressive or relapsed P-LPD has yet to be defined, although some strategies, such as ABVD for HLL and R-CHOP for P-LPD, have been successful. Patients with MTX-P-LPD are also described in several reports. $57,85,86$

\section{MTX-EBVMCU}

EBVMCU is a newly recognized clinicopathological entity in the 2017 WHO classification occurring in elderly patients or due to ISD administration. ${ }^{1}$ However, our understanding of this disease is limited because of its broad clinical and pathological features. Data for 32 cases of MTXEBVMCU are presented in Table 5..$^{78,87-97}$ Twenty-seven female and five male patients were included. The mean age (70 years) was higher than that for other subtypes. Twentyeight patients had RA, and they all had dermatomyositis, PM, Crohn's disease, and Sjögren's syndrome. The oral mucosa was the principal site, and cases involving the tongue, skin, eyelid, lip, nose, buccal mucosa, colon, rectum, or lung were also reported. Among 32 cases, 26 cases were in R-G, whereas 1 case, 4 cases, and 1 case were in R/R-G, P-G and Ch-G, respectively. Regarding chemotherapy, R-CHOP and ABVD were used for patients in $\mathrm{P}-\mathrm{G}$, and ABVD was used for patients in R/R-G (Table 5). The survival rate was $97 \%$ (31/32), but one patient died due to disease progression. Daroontum et al. reported a patient with MTX-EBVMCU who developed EBV+ P-LPD and EBV+DLBCL within 3 years. ${ }^{95}$ Similar to MTX-P-LPD, chemotherapy for aggressive MTX-EBVMCU is decided according to the pathological features of M-LPD such as DLBCL and CHL. In this analysis, such chemotherapy was found to be effective for aggressive MTX-EBVMCU; however, whether the strategy of chemotherapy based on pathological features is suitable for MTX-EBVMCU requires further investigation. Other MTX-EBVMCU cases have been reported. ${ }^{22,65,78,99-111}$ Sinit et $a l$. reviewed 100 patients with EBVMCU separated by age, ISD, and primary/acquired immunodeficiency. ${ }^{112}$

\section{MTX-ND / RH / non-specific (NS) - LPD}

ND-LPD in PTLD is categorized into three subtypes, plasmacytic hyperplasia, infectious mononucleosis, and florid follicular hyperplasia. ${ }^{1}$ In contrast, it is not defined for OIIA-LPD in the WHO classification, although it is common. Several cases of MTX-ND-LPD as RH or NS have been reported. ${ }^{15,16,57}$ In our study, nine patients with MTX-NSLPD were detected among 62 patients with MTX-LPD (14.5\%), with the third highest incidence following DLBCL and CHL (Table 3). ${ }^{16}$ The mean age was 65 years, and the AIDs included 8 cases of RA and 1 case of psoriasis vulgaris. The mean duration of RA and MTX administration was 16 years and 8.9 years, respectively. The CS of 6 patients was 1 or 2, and 3 patients had CS 4 . Four of 7 (57\%) patients were $\mathrm{EBV}+$. Eight patients were categorized into R-G, whereas one patient who died due to EBV-LPD after RRE was categorized into R/R-G (Table 4). In our series, the median serum LDH, CRP, and sIL-2R in these 9 patients were 243 (range, 170-414) U/L, 2.0 (range, 0.3-9) $\mathrm{mg} / \mathrm{dL}$, and 1810 (range, 716-4510) U/L, respectively. ${ }^{16}$ In a report by Kurita et al., all 28 MTX-RH-LPD patients with ND-LPD survived without chemotherapy, although 3 patients (11\%) had stage IV disease. ${ }^{15}$

Regarding the management of MTX-ND/RH/NS-LPD, 


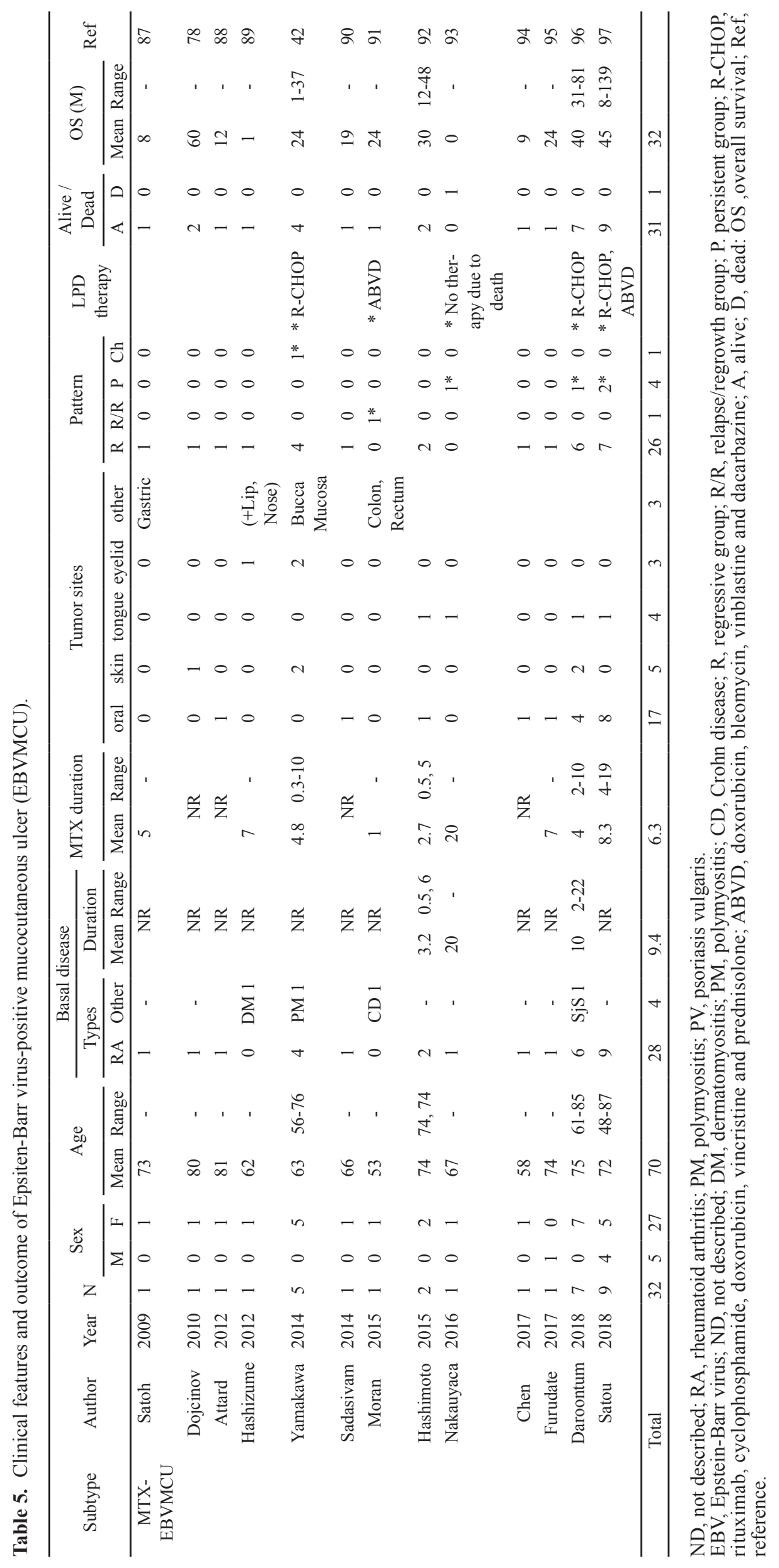


WW is useful because the major clinical course of this subtype is R-G. Similar to P-LPD, the strategy for patients with aggressive or relapsed MTX-ND/RH/NS-LPD is not defined. In previous reports, a number of other cases were demonstrated to be MTX-LPD. ${ }^{110-125}$ We treated several patients with MTX-ND-LPD that changed to CHL during the clinical course; one patient developed severe EBV infection, and 2 diagnosed with ND-MTX-LPD developed CHL during WW. ${ }^{126}$ The remaining issues, such as the definition of this category and management of aggressive MTX-ND/RH/ NS-LPD, along with other issues specific to each type of MTX-LPD require further investigation.

\section{Other MTX-LPD}

Several other subtypes of MTX-LPD, including low grade B cell lymphomas, such as follicular lymphoma (FL), $, 1,2,19,57,65,71$ mucosa-associated lymphoid tissue (MALT) lymphoma, ${ }^{1,2,19,36,57,65,66,71,127-129}$ Burkitt lymphoma (BL), ${ }^{1,2,57,130}$ intravascular lymphoma (IVL), ${ }^{131,132}$ lymphoplasmacytic lymphoma, ${ }^{65}$ plasmablastic lymphoma, ${ }^{19,71}$ adult T-cell leukemia/ lymphoma (ATLL), ${ }^{133}$ angioimmunoblastic T-cell lymphoma (AITL), $, 2,2134,135$ anaplastic large cell lymphoma, , 1,265,136,137 subcutaneous panniculitis-like T-cell lymphoma (SPLTCL), ${ }^{138}$ peripheral T-cell lymphoma (PLCL), $, 1,2,19,36,37,57,139-141$ and extranodal natural killer/T (NK/T)-cell lymphoma, ${ }^{1,2,66,71,142-144}$ have been reported. Their clinical patterns vary. Regressive LPD after MTX withdrawal develops in FL, MALT lymphoma, ATLL, NK/T-cell lymphoma, SPLTCL, and PLTL, whereas some diseases relapse. In contrast, some patients with BL, IVL, or NK/T-cell lymphoma were classified into P-G. EBV was detected in MTX-low-grade lymphomas, which is commonly negative in de novo low-grade lymphomas. For example, EBV $+\mathrm{FL}^{1}$ and MALT lymphoma cases in $\mathrm{R}-\mathrm{G}$ that are EBV+ have been reported. ${ }^{129}$ Regarding LPD regression, EBV-negative LPD, including NK/ T-lymphoma and PTCL, also have a regressive phase. ${ }^{66,141}$ Due to the small number of patients and the limited information on each subtype, assessment of optimal clinical management, such as WW or chemotherapy when LPD develops, requires further investigation in a larger patient population.

\section{NON-MTX-LPD}

A number of studies described non-MTX-LPD in comparison with MTX-LPD, although non-MTX-LPD-to-MTXLPD ratios vary. ${ }^{23,24,57,65,66,71,128}$ For example, Yamada et al. reviewed the background of OIIA-B-LPD, ${ }^{23}$ and described that $25 \%$ of OIIA-LPD is associated with non-MTX drugs. Ichikawa et al. reported 17 patients with non-MTX-associated LPD among 102 patients with OIIA-LPD. ${ }^{57}$ Furthermore, it is well established that AIDs other than RA develop in LPD patients during ISD treatment. ${ }^{145-153}$ In addition, many cases of AIDs in regressive LPD patients after the withdrawal of non-MTX ISDs have been reported, suggesting the immunosuppressive effects leading to LPD development. ${ }^{81,154-161}$ The history of MTX administration should be carefully assessed in patients with non-MTX-LPD because RRE occurs within several years after the withdrawal of MTX, especially in patients with RA.

\section{CLINICAL MTX-LPD}

In clinical practice, symptoms resembling LPD, and laboratory data, such as fever, lymphadenopathy, respiratory symptoms, and increased serum LDH/CRP/sIL-2R levels, are not rare. These manifestations may also develop in the pathogeneses of viral infection and AID activity. As a first step, drug withdrawal is tentatively attempted when such manifestations develop, similar to MTX-LPD. In addition, tissue biopsy should be performed to confirm the diagnosis; however, biopsy may fail for patients with rapid LPD regression after MTX withdrawal. ${ }^{44}$ We analyzed such patients as the clinical MTX-LPD (c-MTX-LPD) group, composed of suspicious-LPD and proven-LPD (Figure 3). ${ }^{162}$ MTX was withdrawn at the time of suspicious-LPD, and some of those with suspicious-LPD developed MTX-LPD, as confirmed by tissue biopsy (proven-LPD). Among the 28 patients with c-MTX-LPD, 7 developed proven-LPD after suspicious-LPD regression, 6 of whom had CHL and one who had plasmablastic lymphoma. Four of the 7 patients with proven$\mathrm{LPD}(+)$ died, whereas all patients with proven-LPD(-) survived. The clinical manifestations included fever, increased serum CRP $(>5 \mathrm{mg} / \mathrm{dL})$, and sIL-2R level $>4000 \mathrm{U} / \mathrm{L}$ at the time of recurrence, resembling LPD symptoms, suggesting the development of proven-LPD. ${ }^{162}$ Although the reason is unclear, the subtypes, including EBV+ DLBCL, DLBCL -NOS, P-LPD, and EBVMCU, did not develop under clinical management with prompt MTX withdrawal. As the incidence of R/R-G among these subtypes was low (Tables 2, 4, and 5), such LPD may include suspicious c-MTX-LPD.

\section{Anti-AID therapy after the development of MTX-LPD}

AID activity commonly flares within one year after AID withdrawal in R-G or after chemotherapy in R/R-G and P-G. Thus, safe ISD usage without inducing LPD after OIIA-LPD

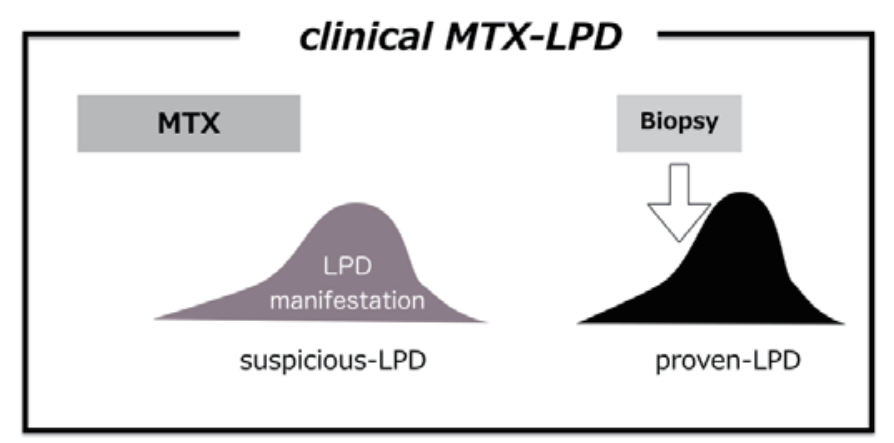

Fig. 3. Clinical methotrexate-associated lymphoproliferative disorders (c-MTX-LPD) ${ }^{162}$

Under MTX administration, MTX withdrawal is attempted when LPD or LPD-like manifestations occur (suspicious-LPD). However, MTX withdrawal often induces prompt regression of suspiciousLPD, making tissue biopsy impossible. After regression of suspicious-LPD, LPD occasionally recurs as relapse/regrowth event, resulting in the LPD diagnosis by tissue biopsy (proven-LPD). 
development has been investigated. The guidelines of the American College of Rheumatology (2015) described several points regarding the usage of AIDs after OIIA-LPD development: very low quality evidence of ISD usage after OIIALPD, a possible increased risk of lymphoma associated with TNFi, and no evidence of increased risk by abatacept (ABT) or tocilizumab (TCZ). ${ }^{163}$ The guidelines of the Japan College of Rheumatology state that ISDs should be avoided as much as possible, and MTX and TNFi are not generally recommended. ${ }^{164,165}$ As many factors, such as type of AID, LPD subtype, ISD dose and duration, EBV activity, ALC in $\mathrm{PB}$, and age, may be related to the development or relapse of OIIA-LPD, a complete understanding of AID usage after OIIA-LPD is difficult. In the analysis of c-MTX-LPD, seven ISDs, tacrolimus (FK), bucillamine (BUC), salazosulfapyridine (SSZ), infliximab (IFX), ABT, iguratimod (IGU), and adalimumab, were combined with MTX. ${ }^{162}$ Thirteen types of ISDs were administered after suspicious-LPD, and 21 patients without proven-LPD received 12 ISDs, MTX, FK, BUC, SSZ, IFX, ABT, IGU, etanercept (ETN), golimumab, TCZ, certolizumab pegol, or tofacitinib, after suspicious-LPD regression. On the other hand, 7 patients with proven-LPD received FK, BUC, SSZ, or ETN, which were also administered to patients without proven-LPD. For patients with RA-MTX-LPD in CR, a difference between AIDs before and after MTX-LPD development was not observed. ${ }^{162}$ From these data, it is difficult to identify the roles of specific ISDs in MTX-LPD development after MTX withdrawal.

\section{PREDICTION OF MTX-LPD}

Although the prediction of MTX-LPD is essential to prevent a poor prognosis due to AIDs, no concrete assessment is available. As mentioned earlier, a decrease in ALC in PB is one candidate, although this method is difficult to apply to P-G. ${ }^{27,29}$ Based on the higher incidence of OIIA-LPD in Japan, several studies have focused on human leukocyte antigen (HLA) analysis. Yamakawa et al. analyzed 20 Japanese patients with MTX-LPD, and found that the allele $B * 15: 11$ is closely related to EBV infection. ${ }^{42}$ Another HLA study on
25 patients with MTX-LPD identified 11 alleles, including A*2402 and DRB $1 * 0405$, that were significantly more commonly detected than in the general population. ${ }^{16}$ However, data on HLA alleles are inconsistent between these two studies. Regarding PTLD, several studies suggested the possibility of prediction of LPD by measuring the EBV viral load; ${ }^{166-169}$ however, standardization of the EBV assay and cut-off values for positive selection are of concern. Impairment due to EBV, as indicated by impaired T-cell response against EBV and increased EBV viral load after MTX administration, has been reported in patients with RA, ${ }^{170-175}$ and several reports demonstrated the association between EBV viral road and disease activity in patients with juvenile idiopathic arthritis who developed MTX-LPD. ${ }^{176}$ In contrast, several recent studies reported that the EBV viral load does not increase under the administration of ISDs such as MTX, TNFi, and ABT. ${ }^{177-179}$

\section{SUMMARY}

The data presented in this article are summarized in Table 6 , and the specific features of MTX-LPD based on the previous data, including this review, are listed in Table 7. The proposal for clinical management of MTX-LPD is presented in Figure 4. When c-MTX-LPD develops, the first step is the withdrawal of MTX, in addition to differential diagnosis by annual health checks, laboratory investigations, such as serum LDH, CRP, sIL-2R levels, and other examinations for viral infections, basal disease activity, and other considered diseases. Imaging, including computer tomography and positron-emission tomography, is also used for the differential diagnosis. Examinations of bone marrow aspiration/biopsy and the measurement of EBV viral load are performed if necessary. To make a definite diagnosis of LPD, tissue biopsy is required at any time during the clinical course. After withdrawal of MTX, chemotherapy is administered to patients with non-regressive or aggressive LPD (P-G), whereas patients achieving complete response (CR) are followed-up without additional chemotherapy. When LPD relapses or recurs, chemotherapy is initiated $(\mathrm{R} / \mathrm{R}-\mathrm{G})$. In contrast, the duration of WW is an important issue among patients with

Table 6. Summary of methotrexate associated lymphoproliferative disorders (MTX-LPDs)

\begin{tabular}{|c|c|c|c|c|c|c|c|c|c|c|c|c|c|c|c|c|}
\hline \multirow[b]{2}{*}{ MTX-LPD } & \multirow[b]{2}{*}{$\mathrm{N}$} & \multirow{2}{*}{$\begin{array}{c}\text { Female } \\
(\%)\end{array}$} & \multirow{2}{*}{$\begin{array}{l}\text { Age* } \\
(\mathrm{y})\end{array}$} & \multirow{2}{*}{$\begin{array}{c}\text { Basal } \\
\text { disease* } \\
(y)\end{array}$} & \multirow{2}{*}{$\begin{array}{c}\text { MTX } \\
\text { dura- } \\
\text { tion* (y) }\end{array}$} & \multirow{2}{*}{$\begin{array}{c}\text { CS } \\
3 \text { or } 4\end{array}$} & \multirow{2}{*}{$\begin{array}{c}\mathrm{EBV}+ \\
(\%)\end{array}$} & \multicolumn{4}{|c|}{ Clinical course $(\%)$} & \multicolumn{5}{|c|}{ Survival rate $(\%)$} \\
\hline & & & & & & & & R-G & $\mathrm{R} / \mathrm{R}-\mathrm{G}$ & P-G & Ch-G & All & R-G & $\mathrm{R} / \mathrm{R}-\mathrm{G}$ & P-G & Ch-G \\
\hline EBV+DLBCL & 66 & 71 & 68 & 13.5 & 6.1 & 62 & 100 & 62 & 3 & 17 & 17 & 91 & 95 & 100 & 72 & 90 \\
\hline DLBCL-NOS & 50 & 59 & 66 & 11.1 & 5.4 & 60 & 0 & 26 & 6 & 36 & 26 & 60 & 100 & 67 & 72 & 53 \\
\hline CHL & 51 & 74 & 62 & 13 & 5.6 & 75 & 76 & 14 & 40 & 24 & 21 & 78 & 100 & 65 & 67 & 100 \\
\hline P-LPD & 17 & 64 & 65 & 11 & 7.2 & 64 & 100 & 76 & 18 & 0 & 6 & 82 & 92 & 33 & - & 0 \\
\hline EBVMUCU & 32 & 84 & 70 & 9.4 & 6.3 & $-* *$ & 100 & 81 & 3 & 13 & 3 & 97 & 100 & 100 & 75 & 100 \\
\hline NS-LPD & 9 & 56 & 65 & 16 & 8.9 & 33 & 57 & 89 & 11 & 0 & 0 & 89 & 100 & 0 & - & - \\
\hline Total & 225 & 70 & 66 & 12.5 & 6.1 & 54.7 & 70.6 & 48 & 13.5 & 20.3 & 16.4 & 81.3 & 97.2 & 67.7 & 67.2 & 81 \\
\hline
\end{tabular}

EBV, Epstein-Barr virus; DLBCL, diffuse large B cell lymphoma; NOS, not otherwise specified; CHL, classical Hodgkin lymphoma; P-LPD, polymorphic LPD; EBVMCU, EEBV-positive mucocutaneous ulcer; CS, clinical stage; R-G, regression group; R/R-G, relapse/regrowth group; P-G, persistent group; Ch-G, chemotherapy group.

$*$ indicated mean values. $* *$ involved sites were mainly oral cavity and/or skin. 
Table 7. Clinicopathological features of methotrexate-associated lymphoproliferative disorders (MTX-LPDs)

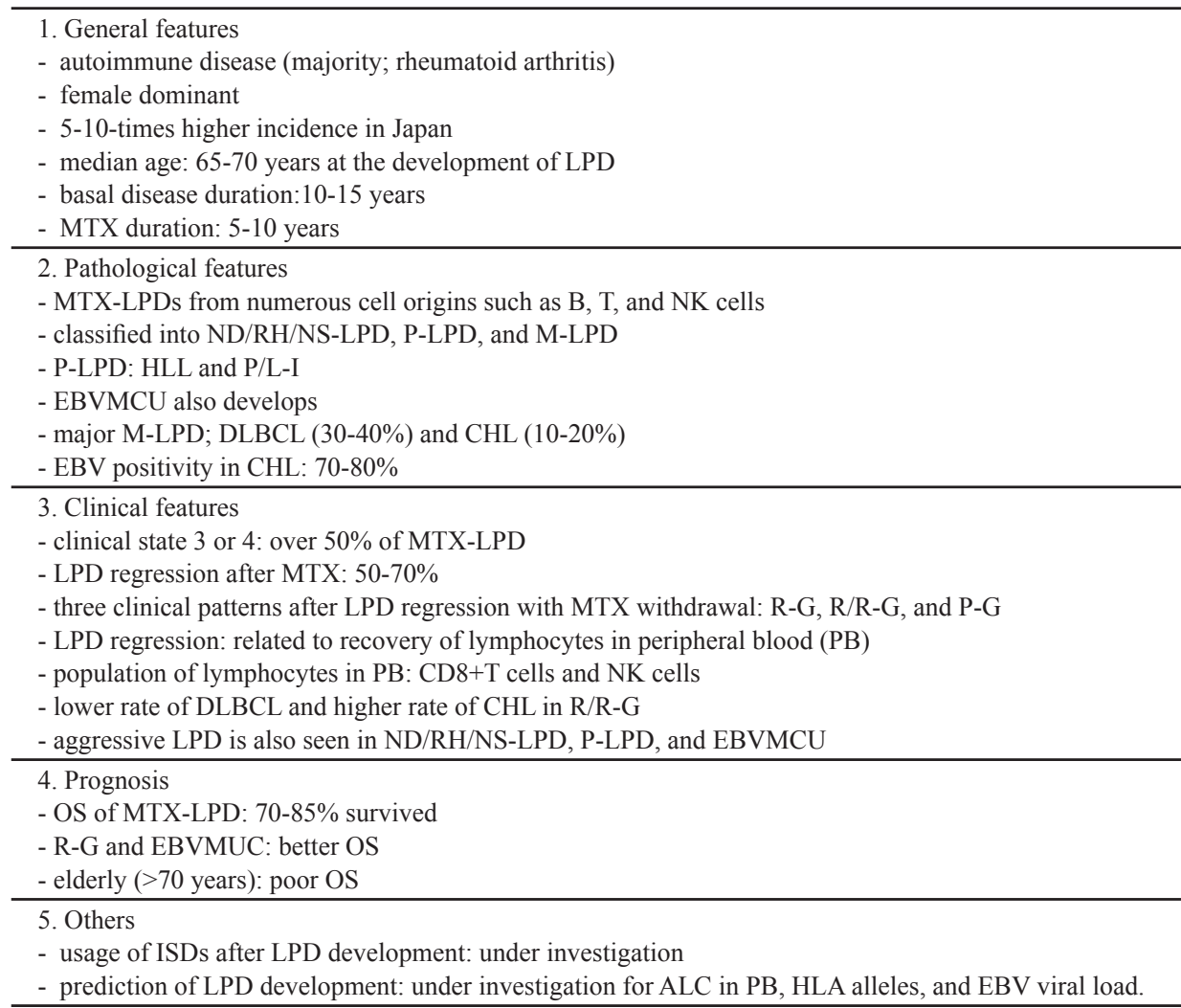

NK, natural killer; ND, non-destructive; RH, reactive hyperplasia; NS, non-specific; P-LPD, polymorphic LPD; M-LPD, monomorphic LPD; HLL, Hodgkin-like lesions; P/L-I; polymorphic/ lymphoplasmacytic infiltrates; EBVMCU; Epstein-Barr virus-positive mucocutaneous ulcer; DLBCL, diffuse large B cell lymphoma; CHL, classical Hodgkin lymphoma; R-G, regressive group; R/R-G, relapse/regrowth group; P-G. persistent group; ISD, immunosuppressive drug; ALC, absolute lymphocyte count; HLA, human leukocyte antigen.

residual tumor burden under LPD regression. The management of patients with responses less than CR state after MTX withdrawal is dependent on the physician's decision whether chemotherapy is required under such situation. In our report, the recovered ALC in PB lasted for at least 2 years in patients with MTX-LPD in R-G, and it gradually decreased after 6 months of MTX withdrawal toward RRE in R/R-G. ${ }^{30}$ Because the pathogenesis of LPD regression is complexed on the basis of various factors, including LPD subtypes, LDP tumor burden, EBV activation, types or combination of ISDs, and $\mathrm{ALC}$ in $\mathrm{PB}$, the definite answer for the duration of $\mathrm{WW}$ is not concluded yet. Regarding non-MTX-LPD, the patient accumulation is required to conclude the precious assessment, although the management of non-MTX-LPD might be based on that of MTX-LPD.

The pathogenesis of MTX-LPD and related factors are illustrated in Figure 5. Impairment by EBV, the chronic inflammation process in AIDs, immune abnormality, including genetic background, such as HLA restriction, and aging may underlie IA-LPD. ISD administration accelerates the impairment of anti-LPD immunity, and consequently, LPD develops. The duration between ISD administration and LPD development ranges widely from a few months to over
30 years; therefore, triggers, including a decrease in ALC in PB, may occur at the time of LPD development. After ISD withdrawal, LPD regresses in $\mathrm{R}-\mathrm{G}$ and $\mathrm{R} / \mathrm{R}-\mathrm{G}$, but not in P-G. Lymphocytes, such as CD8+ T cells and NK cells, play important roles in LPD regression. When ISDs are administered for AID activity after LPD development, no RRE occurs if the potent immunity against LPD remains (R-G), whereas loosing anti-LPD immunity is categorized in R/R-G. After MTX-LPD development, several factors, such as the subtypes of MTX-LPD, decrease in ALC in PB, EBV reactivation, and impairment of anti-LPD immunity mediated by ISDs, may influence RRE. Although the disease entity of MTX-LPD is still controversial, the phenomenon of regression after withdrawing ISDs suggests the direct influence of MTX on LPD development. MTX-LPD is an important adverse event in AIDs, resulting in a poor outcome.

On the other hand, many ISDs, including MTX and TNFi, have significantly improved the quality of life and OS of patients with AIDs, especially RA. To establish a safe AIDs treatment for patients developing MTX-LPD, issues, such as a standard therapy for each subtype of MTX-LPD, the validation of predictive factors, including ALC, HLA alleles, EBV viral load, and the estimation of OS under 


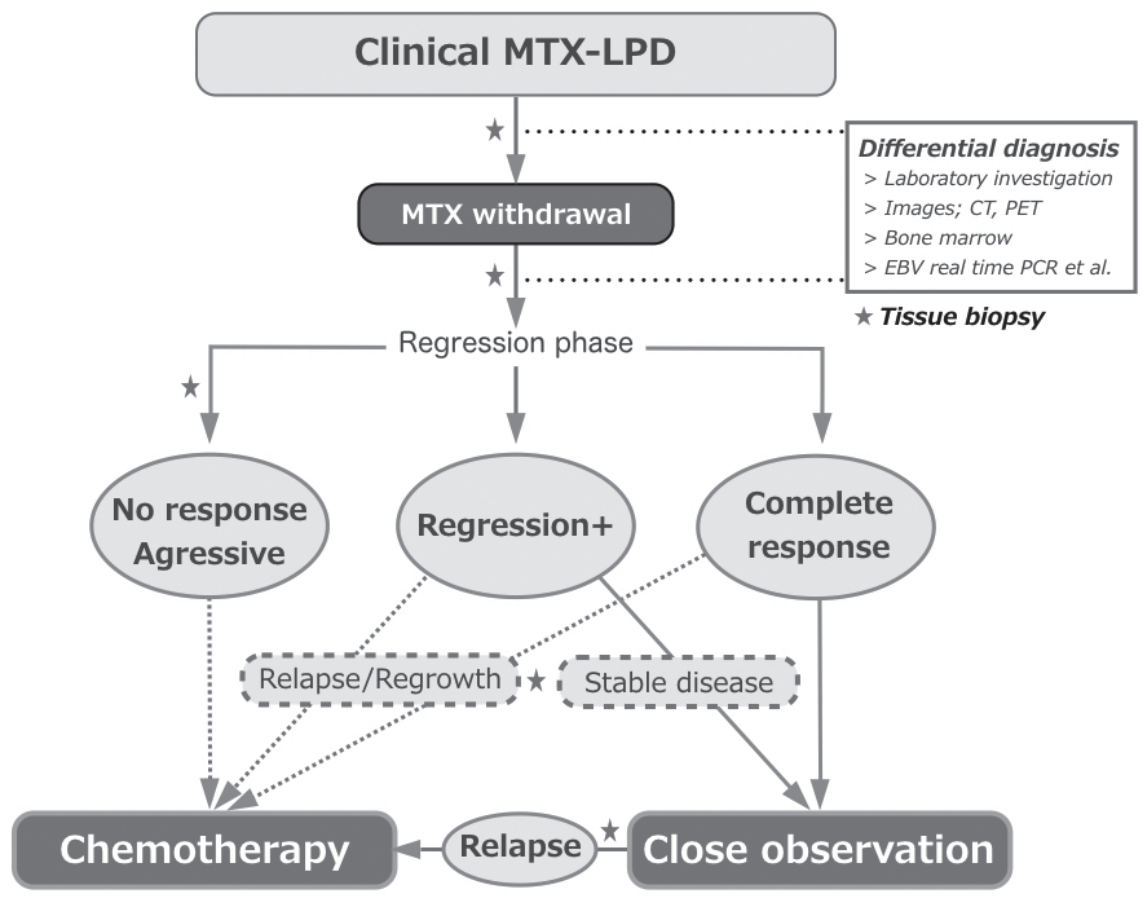

Fig. 4. Clinical management of methotrexate-associated lymphoproliferative disorders (MTX-LPD)

When clinical-MTX-LPD develops, MTX withdrawal is the first procedure. In addition to watchful waiting, the differential diagnosis is performed by laboratory investigation and imaging. Bone marrow aspiration/biopsy and the measurement of EBV viral load are considered according to the patient's clinicopathogenesis. To diagnose LPD, tissue biopsy is required at any time during the clinical course. After MTX withdrawal, chemotherapy is considered for patients with non-regressive LPD or aggressive LPD, and relapse/regrowth after the regressive phase. Among patients with residual LPD under LPD regression, the decision for chemotherapy is based on the physician's assessment.

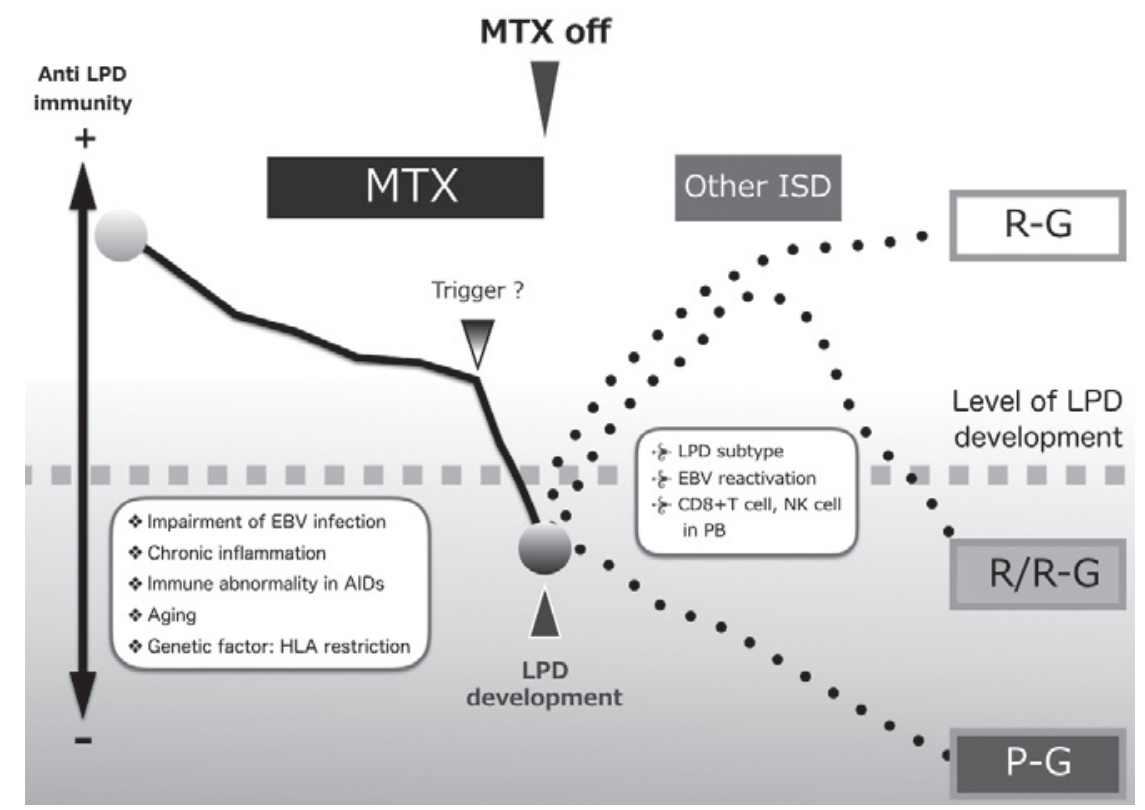

Fig. 5. Pathogenesis of methotrexate-associated lymphoproliferative disorders (MTX-LPD)

Regarding the development of MTX-LPD, impairment by EBV, the chronic inflammation process in autoimmune diseases (AIDs), immune abnormality in AIDs, including genetic background, such as human leukocyte antigen (HLA) restriction, may be underlying factors. Immune suppressive drugs (ISDs), including methotrexate (MTX), accelerate the impairment of anti-LPD immunity, and consequently, LPD develops Triggers, including a decrease in the absolute lymphocyte count (ALC) in peripheral blood (PB), may occur at the time of LPD development After ISD withdrawal, LPD regression occurs in the regressive group (R-G) and relapse/regrowth group (R/R-G), but not in the persistent group (P-G). Lymphocytes, such as CD8+ T cells and natural killer (NK) cells, play important roles in LPD regression. When ISDs are administered for AID activity after LPD development, no relapse/regrowth event (RRE) occurs if the potent immunity against LPD remains (R-G), whereas the loss of anti-LPD immunity is categorized in R/R-G. After MTX-LPD development, several factors, such as the subtypes of MTX-LPD, decrease in ALC in PB, EBV reactivation, and impairment of anti-LPD immunity mediated by ISDs, may influence RRE. 
long-term observation, need to be assessed to discriminate among MTX-LPD subtypes. In addition, the clinical assessment of non-MTX-LPD is another important issue in OIIALPD. As several clinical questions regarding OIIA-LPD, such as whether the management of non-MTX-LPD is similar to that of MTX-LPD, remain, further analyses will be performed for their clarification.

\section{CONFLICT OF INTEREST}

TJ received honoraria from Takeda Pharmaceutical Company Limited. The remaining authors declare no competing financial interests.

\section{REFERENCES}

1 Swerdlow SH, Campo E, Harris NL, et al. WHO Classification of Tumors of Haematopoietic and Lymphoid Tissues. Immunodeficiency-associated lymphoproliferative disorders. revised 4th ed, IARC publications. 2017; pp. 443-464.

2 Swerdlow SH, Campo E, Harris NL, et al. WHO Classification of Tumors of Haematopoietic and Lymphoid Tissues. Immunodeficiency-associated lymphoproliferative disorders. 4th ed, IARC publications. 2008. pp. 335-351.

3 Harigai M. Lymphoproliferative disorders in patients with rheumatoid arthritis in the era of widespread use of methotrexate: A review of the literature and current perspective. Mod Rheumatol. 2018; $28: 1-8$

4 Balandraud N, Guis S, Meynard JB, et al. Long-term treatment with methotrexate or tumor necrosis factor $\alpha$ inhibitors does not increase epstein-barr virus load in patients with rheumatoid arthritis. Arthritis Rheum. 2007; 57 : 762-767.

5 Yoshida Y, Takahashi Y, Yamashita H, et al. Clinical characteristics and incidence of methotrexate-related lymphoproliferative disorders of patients with rheumatoid arthritis. Mod Rheumatol. 2014; $24:$ 763-765.

6 Hashimoto A, Chiba N, Tsuno H, et al. Incidence of malignancy and the risk of lymphoma in Japanese patients with rheumatoid arthritis compared to the general population. J Rheumatol. 2015; $42:$ :564-571

7 Simon TA, Thompson A, Gandhi KK, Hochberg MC, Suissa S. Incidence of malignancy in adult patients with rheumatoid arthritis: a meta-analysis. Arthritis Res Ther. 2015; $17: 212$.

8 Harigai M, Nanki T, Koike R, et al. Risk for malignancy in rheumatoid arthritis patients treated with biological diseasemodifying antirheumatic drugs compared to the general population: A nationwide cohort study in Japan. Mod Rheumatol. 2016; $26: 642-650$.

9 Hellgren K, Baecklund E, Backlin C, et al. Rheumatoid arthritis and risk of malignant lymphoma: Is the risk still increased? Arthritis Rheumatol. 2017; 69 : 700-708.

10 Shimizu Y, Nakajima A, Inoue E, et al. Characteristics and risk factors of lymphoproliferative disorders among patients with rheumatoid arthritis concurrently treated with methotrexate: a nested case-control study of the IORRA cohort. Clin Rheumatol. 2017; 36 : 1237-1245.

11 Chisaki Y, Aoji S, Yano Y. Analysis of adverse drug reaction risk in elderly patients using the Japanese adverse drug event report (JADER) Database. Biol Pharm Bull. 2017; 40 : 824-829.

12 Mercer LK, Regierer AC, Mariette X, et al. Spectrum of lymphomas across different drug treatment groups in rheumatoid arthritis: a European registries collaborative project. Ann Rheum Dis. 2017; 76 : 2025-2030.

13 Baecklund E, Iliadou A, Askling J, et al. Association of chronic inflammation, not its treatment, with increased lymphoma risk in rheumatoid arthritis. Arthritis Rheum. 2006; 54 : 692-701.

14 Jaffe ES, Stein H, Vardiman JW. Pathology and Genetics of Tumours of Haematopoietic and Lymphoid Tissues. Immunodeficiency-associated lymphoproliferative disorders. 3rd ed, IARC publications. 2001; pp. 256-271.

15 Kurita D, Ichikawa A, Sasaki Y, et al. Clinicopathological Study of Methotrexate-Associated Lymphoproliferative Disorders in Rheumatoid Arthritis Patients: Histological Classification and Predictive Factors for Disease Progression. ASH meeting. Atlanta, \#4168, 2017.

16 Tokuhira M, Saito S, Okuyama A, et al. Clinicopathologic investigation of methotrexate-induced lymphoproliferative disorders, with a focus on regression. Leuk Lymphoma. 2018; 59 : 1143-1152.

17 DeStefano CB, Desai SH, Shenoy AG, Catlett JP. Management of post-transplant lymphoproliferative disorders. Br J Haematol. 2018; $182: 330-343$.

18 Pfizer-Japan-Inc: Rheumatrex Proper Use Information. In: vol 21, Tokyo. 2014.

19 Tokuhira M, Watanabe R, Nemoto T, et al. Clinicopathological analyses in patients with other iatrogenic immunodeficiencyassociated lymphoproliferative diseases and rheumatoid arthritis. Leuk Lymphoma. 2012; 53 : 616-623.

20 Ando M, Sato Y, Takata K, et al. A20 (TNFAIP3) deletion in Epstein-Barr virus-associated lymphoproliferative disorders/ lymphomas. PLoS One. 2013; 8 : e56741.

21 Carreras J, Yukie Kikuti Y, Miyaoka M, et al. Genomic profile and pathologic features of diffuse large B-cell lymphoma subtype of methotrexate-associated lymphoproliferative disorder in rheumatoid arthritis patients. Am J Surg Pathol. 2018; 42 : 936-950.

22 Koens L, Senff NJ, Vermeer MH, Willemze R, Jansen PM. Methotrexate-associated B-cell lymphoproliferative disorders presenting in the skin: A clinicopathologic and immunophenotypical study of 10 cases. Am J Surg Pathol. 2014; 38 : 999-1006.

23 Yamada K, Oshiro Y, Okamura S, et al. Clinicopathological characteristics and rituximab addition to cytotoxic therapies in patients with rheumatoid arthritis and methotrexate-associated large B lymphoproliferative disorders. Histopathology. 2015; 67 : 70-80.

24 Ejima-Yamada K, Oshiro Y, Okamura S, et al. Epstein-Barr virus infection and gene promoter hypermethylation in rheumatoid arthritis patients with methotrexate-associated B cell lymphoproliferative disorders. Virchows Arch. 2017; 470 : 205-215.

25 Gion Y, Iwaki N, Takata K, et al. Clinicopathological analysis of methotrexate-associated lymphoproliferative disorders: Comparison of diffuse large B-cell lymphoma and classical Hodgkin lymphoma types. Cancer Sci. 2017; 108 : 1271-1280. 
26 Inui Y, Matsuoka H, Yakushijin K, et al. Methotrexateassociated lymphoproliferative disorders: management by watchful waiting and observation of early lymphocyte recovery after methotrexate withdrawal. Leuk Lymphoma. 2015; 56 : 3045-3051.

27 Saito S, Suzuki K, Yoshimoto K, et al. Restoration of decreased $\mathrm{T}$ helper 1 and CD8+ T cell subsets is associated with regression of lymphoproliferative disorders developed during methotrexate treatment. Front Immunol. 2018; $9: 621$.

28 Takanashi S, Aisa Y, Ito C, et al. Clinical characteristics of methotrexate-associated lymphoproliferative disorders: relationship between absolute lymphocyte count recovery and spontaneous regression. Rheumatol Int. 2017; 37 : 1629-1633.

29 Saito S, Kaneko Y, Yamaoka K, Tokuhira M, Takeuchi T. Distinct patterns of lymphocyte count transition in lymphoproliferative disorder in patients with rheumatoid arthritis treated with methotrexate. Rheumatology. (Oxford) 2017; $56: 940-946$.

30 Tokuhira M, Tanaka Y, Takahashi Y, et al. The Absolute Count of Lymphocytes Is a Strong Predictive Factor for Relapse/ Regrowth Events and Outcomes in Patients with Regressive Methotrexate-Associated Lymphoproliferative Disorders ASH meeting. San Diego, \#1589, 2018.

31 Hasenclever D, Diehl V, Armitage JO, et al. A prognostic score for advanced Hodgkin's disease. International prognostic factors project on advanced Hodgkin's disease. N Engl J Med. 1998; 339: 1506-1514.

32 Ho CL, Lu CS, Chen JH, et al. Neutrophil/lymphocyte ratio, lymphocyte/monocyte ratio, and absolute lymphocyte count/ absolute monocyte count prognostic score in diffuse large B-cell lymphoma: Useful prognostic tools in the rituximab era. Medicine (Baltimore). 2015; 94 : e993.

33 Vassilakopoulos TP, Dimopoulou MN, Angelopoulou MK, et al. Prognostic implication of the absolute lymphocyte to absolute monocyte count ratio in patients with classical Hodgkin lymphoma treated with doxorubicin, bleomycin, vinblastine, and dacarbazine or equivalent regimens. Oncologist. 2016; 21 : 343-353.

34 Keane C, Tobin J, Talaulikar D, et al. A high LDH to absolute lymphocyte count ratio in patients with DLBCL predicts for a poor intratumoral immune response and inferior survival. Oncotarget. 2018; $9: 23620-23627$.

35 Li N, Zhang L, Song HL, et al. Prognostic impact of absolute lymphocyte count/absolute monocyte count ratio and prognostic score in patients with nasal-type, extranodal natural killer/T-cell lymphoma. Tumour Biol. 2017; 39 : 1010428317705503.

36 Kojima M, Itoh H, Hirabayashi K, et al. Methtrexate-associated lymphoproliferative disorders. A clinicopathological study of 13 Japanese cases. Pathol Res Pract. 2006; 202 : 679-685.

37 Miyazaki T, Fujimaki K, Shirasugi Y, et al. Remission of lymphoma after withdrawal of methotrexate in rheumatoid arthritis: Relationship with type of latent Epstein-Barr virus infection. Am J Hematol. 2007; 82 : 1106-1109.

38 Jois RN, Gaffney K, Cane P, Nicholson AG, Wotherspoon AC. Methotrexate-associated lymphoproliferative disorder masquerading as interstitial lung disease. Histopathology. 2007; 51 : 709-712.

39 Ogasawara T, Kimura A, Yasuyama M, et al. [2-year complete remission after withdrawal of methotrexate in a rectal methotrexate-associated diffuse large B-cell lymphoma]. Rinsho Ketsueki. 2007; 48 : 485-490.

40 Rizzi R, Curci P, Delia M, et al. Spontaneous remission of "methotrexate-associated lymphoproliferative disorders" after discontinuation of immunosuppressive treatment for autoimmune disease. Review of the literature. Med Oncol. 2009; 26 : $1-9$.

41 Ishida M, Hodohara K, Yoshii M, et al. Methotrexate-related Epstein-Barr virus-associated lymphoproliferative disorder occurring in the gingiva of a patient with rheumatoid arthritis. Int J Clin Exp Pathol. 2013; 6 : 2237-2241.

42 Yamakawa N, Fujimoto M, Kawabata D, et al. A clinical, pathological, and genetic characterization of methotrexate-associated lymphoproliferative disorders. J Rheumatol. 2014; 41 : 293-299.

43 Kameda T, Dobashi H, Miyatake N, et al. Association of higher methotrexate dose with lymphoproliferative disease onset in rheumatoid arthritis patients. Arthritis Care Res. (Hoboken) 2014; $66: 1302-1309$.

44 Kawano N, Ono N, Kawano S, et al. Clinical features and outcomes of 9 patients with immunodeficiency-associated lymphoproliferative disorders treated at a single institution. J Clin Exp Hematop. 2014; 54 : 187-196.

45 Kudoh M, Harada H, Matsumoto K, et al. Methotrexateassociated lymphoproliferative disorder arising in the retromolar triangle and lung of a patient with rheumatoid arthritis. Oral Surg Oral Med Oral Pathol Oral Radiol. 2014; 118 : e105-e110.

46 Shimizu S, Inokuma D, Murata J, et al. Cutaneous manifestations of methotrexate-associated lymphoproliferative disorders: report of two cases and a review of the literature. Acta Derm Venereol. 2015; $95: 366-367$

47 Ikeda K, Nakamura T, Kinoshita T, et al. Methotrexate-related lymphoproliferative disorder of the stomach in a patient with rheumatoid arthritis: a case of disease regression after methotrexate cessation. Clin J Gastroenterol. 2016; 9 : 17-21.

48 Matsumoto R, Numata K, Doba N, et al. A case of multiple hepatic lesions associated with methotrexate-associated lymphoproliferative disorder. J Med Ultrason. (2001) 2016; 43 : 545-551.

49 Hatano T, Ohishi M, Yoshimoto G, et al. Methotrexate-related lymphoproliferative disorder presenting with severe swelling of the elbow joint: A case report. JBJS Case Connect. 2017; 7 : e65.

50 Takei D, Abe T, Amano H, et al. Methotrexate-associated primary hepatic malignant lymphoma following hepatectomy: A case report. Int J Surg Case Rep. 2017; 31 : 5-9.

51 Oebisu N, Hoshi M, Ieguchi M, et al. Lymphoproliferative disorder with pathological fracture of the femur in a patient with rheumatoid arthritis treated with methotrexate: A case report. Mol Clin Oncol. 2018; 9 : 187-191.

52 Suzuki E, Kanno T, Kimura S, et al. Methotrexate-associated lymphoproliferative disorder complicated by severe acute respiratory failure and ileal perforation:a case report. Fukushima J Med Sci. 2018; 64 : 82-88.

53 Ebeo CT, Girish MR, Byrd RP, Roy TM, Mehta JB. Methotrexateinduced pulmonary lymphoma. Chest. 2003; $123: 2150-2153$. 
54 Kawahara A, Tsukada J, Yamaguchi T, Katsuragi T, Higashi T. Reversible methotrexate-associated lymphoma of the liver in rheumatoid arthritis: a unique case of primary hepatic lymphoma. Biomark Res. 2015; $3: 10$.

55 Miyagawa K, Shibata M, Noguchi H, et al. Methotrexaterelated primary hepatic lymphoma in a patient with rheumatoid arthritis. Intern Med. 2015; 54 : 401-405.

56 Niitsu N, Okamoto M, Nakamine H, Hirano M. Clinicopathologic correlations of diffuse large B-cell lymphoma in rheumatoid arthritis patients treated with methotrexate. Cancer Sci. 2010; $101: 1309-1313$

57 Ichikawa A, Arakawa F, Kiyasu J, et al. Methotrexate/iatrogenic lymphoproliferative disorders in rheumatoid arthritis: histology, Epstein-Barr virus, and clonality are important predictors of disease progression and regression. Eur J Haematol. 2013; 91 : 20-28.

58 Muto R, Miyoshi H, Sato K, et al. Epidemiology and secular trends of malignant lymphoma in Japan: Analysis of 9426 cases according to the World Health Organization classification. Cancer Med. 2018; 7 : 5843-5858.

59 Dojcinov SD, Venkataraman G, Pittaluga S, et al. Age-related EBV-associated lymphoproliferative disorders in the Western population: a spectrum of reactive lymphoid hyperplasia and lymphoma. Blood. 2011; 117 : 4726-4735.

60 Castillo JJ, Beltran BE, Miranda RN, et al. EBV-positive diffuse large B-cell lymphoma, not otherwise specified: 2018 update on diagnosis, risk-stratification and management. Am J Hematol. 2018; 93 : 953-962.

61 Oyama T, Yamamoto K, Asano N, et al. Age-related EBVassociated B-cell lymphoproliferative disorders constitute a distinct clinicopathologic group: a study of 96 patients. Clin Cancer Res. 2007; 13 : 5124-5132.

62 Kawano N, Ono N, Yoshida S, et al. Successful treatment of immunodeficiency-associated EBV-negative lymphoproliferative disorders in rheumatoid arthritis by methotrexate withdrawal and prevention of its relapse by rituximab administration. J Clin Exp Hematop. 2012; 52 : 193-198.

63 Boulanger E, Rieux-Laucat F, Picard C, et al. Diffuse large B-cell non-Hodgkin's lymphoma in a patient with autoimmune lymphoproliferative syndrome. Br J Haematol. 2001; 113 : 432-434.

64 Lim IG, Bertouch JV. Remission of lymphoma after drug withdrawal in rheumatoid arthritis. Med J Aust. 2002; 177 : 500-501.

65 Hasserjian RP, Chen S, Perkins SL, et al. Immunomodulator agent-related lymphoproliferative disorders. Mod Pathol. 2009; $22: 1532-1540$

66 Kondo S, Tanimoto K, Yamada K, et al. Mature T/NK-cell lymphoproliferative disease and Epstein-Barr virus infection are more frequent in patients with rheumatoid arthritis treated with methotrexate. Virchows Arch. 2013; 462 : 399-407.

67 Tatsumi G, Ukyo N, Hirata H, Tsudo M. Primary hepatic lymphoma in a patient with rheumatoid arthritis treated with methotrexate. Case Rep Hematol. 2014; 2014 : 1-5.

68 Horie N, Kawano R, Kaneko T, Shimoyama T. Methotrexaterelated lymphoproliferative disorder arising in the gingiva of a patient with rheumatoid arthritis. Aust Dent J. 2015; 60 :
408-411.

69 Chang MD, Markham MJ, Liu X. Epstein-Barr virus-positive diffuse large B-cell lymphoma involving the colon in a patient with ulcerative pancolitis and polymyositis on long-term methotrexate therapy. Gastroenterol Res. 2016; $9: 83-86$.

70 Tokuyama K, Okada F, Matsumoto S, et al. EBV-positive MTX-diffuse large B cell lymphoma in a rheumatoid arthritis patient. Jpn J Radiol. 2014; 32 : 183-187.

71 Jeon YW, Yoon JH, Lee SE, et al. Clinical manifestations of autoimmune disease-related non-Hodgkin lymphoma: a Korean single-center, retrospective clinical study. Korean J Intern Med. 2016; 31 : 944-952.

72 Loo EY, Medeiros LJ, Aladily TN, et al. Classical Hodgkin lymphoma arising in the setting of iatrogenic immunodeficiency: a clinicopathologic study of 10 cases. Am J Surg Pathol. 2013; $37: 1290-1297$.

73 Takasumi M, Okai K, Asano T, et al. [A case of methotrexateassociated lymphoproliferative disorder diagnosed by liver biopsy]. Nippon Shokakibyo Gakkai Zasshi. 2015; 112 : 115-122.

74 Tsukazaki Y, Shinohara T, Tanaka K, et al. Hepatosplenic Hodgkin lymphoma without lymphadenopathy following reversible methotrexate-associated lymphoproliferative disorder. Mod Rheumatol. 2017; 27 : 372-375.

75 Eso Y, Uza N, Shirakawa K, et al. Choledochoduodenal fistula during chemotherapy with brentuximab vedotin for methotrexate-associated lymphoproliferative disorder. Intern Med. 2018; 57 : 2203-2207.

76 Nakazato T, Takanashi S, Hirano M, et al. Brentuximab vedotin is effective for rheumatoid arthritis in a patient with relapsed methotrexate-associated Hodgkin lymphoma. Ann Hematol. 2018; 97 : 1489-1491.

77 Svensson AM, Jacobson ER, Ospina D, Tindle BH. Reversible Epstein-Barr virus-negative lymphadenopathy and bone marrow involved by Hodgkin's lymphoma in a rheumatoid arthritis patient undergoing long-term treatment with low-dose methotrexate: a case report and review of the literature. Int J Hematol. 2006; $83: 47-50$

78 Dojcinov SD, Venkataraman G, Raffeld M, Pittaluga S, Jaffe ES. EBV positive mucocutaneous ulcer-a study of 26 cases associated with various sources of immunosuppression. Am J Surg Pathol. 2010; 34 : 405-417.

79 Carbone A, Spina M, Gloghini A, Tirelli U. Classical Hodgkin's lymphoma arising in different host's conditions: pathobiology parameters, therapeutic options, and outcome. Am J Hematol. 2011; $86: 170-179$.

80 Miranda RN, Loo E, Medeiros LJ. Iatrogenic immunodeficiency-associated classical hodgkin lymphoma: clinicopathologic features of 54 cases reported in the literature. Am J Surg Pathol. 2013; 37 : 1895-1897.

81 Komatsuda A, Wakui H, Nimura T, Sawada K. Reversible infliximab-related lymphoproliferative disorder associated with Epstein-Barr virus in a patient with rheumatoid arthritis. Mod Rheumatol. 2008; $18: 315-318$

82 Ohkura Y, Shindoh J, Haruta S, et al. Primary adrenal lymphoma possibly associated with Epstein-Barr virus reactivation due to immunosuppression under methotrexate therapy. 
Medicine (Baltimore). 2015; 94 : e1270.

83 Yamakawa H, Yoshida M, Katagi H, et al. Pulmonary and retroperitoneal lesions induced by methotrexate-associated lymphoproliferative disorder in a patient with rheumatoid arthritis. Mod Rheumatol. 2016; 26 : 441-444.

84 Tsukui D, Kanda H, Shinozaki-Ushiku A, et al. Polymorphic lymphoproliferative disorders in patients with rheumatoid arthritis are associated with a better clinical outcome. Mod Rheumatol. 2018; $28: 621-625$.

85 Kikuchi K, Miyazaki Y, Tanaka A, et al. Methotrexate-related Epstein-Barr Virus (EBV)-associated lymphoproliferative disorder-so-called "Hodgkin-like lesion"-of the oral cavity in a patient with rheumatoid arthritis. Head Neck Pathol. 2010; 4 : 305-311.

86 Takemori N, Kaneko H, Nakamura M, Kojima M. Complete remission of methotrexate-related Epstein-Barr-virus-associated Hodgkin-like lymphoma following withdrawal of MTX coupled with clarithromycin administration. Case Rep Hematol. 2012; 2012:1-6.

87 Satoh K, Yoshida N, Imaizumi K, et al. Reversible methotrexate-associated lymphoproliferative disorder resembling advanced gastric cancer in a patient with rheumatoid arthritis. Am J Med Sci. 2009; 338 : 334-335.

88 Attard AA, Praveen P, Dunn PJS, James GJ. Epstein-Barr viruspositive mucocutaneous ulcer of the oral cavity: the importance of having a detailed clinical history to reach a correct diagnosis. Oral Surg Oral Med Oral Pathol Oral Radiol. 2012; 114 : e37-e39.

89 Hashizume H, Uchiyama I, Kawamura T, et al. Epstein-Barr virus-positive mucocutaneous ulcers as a manifestation of methotrexate-associated B-cell lymphoproliferative disorders. Acta Derm Venereol. 2012; $92: 276-277$.

90 Sadasivam N, Johnson RJ, Owen RG. Resolution of methotrexate-induced Epstein-Barr virus-associated mucocutaneous ulcer. Br J Haematol. 2014; 165 : 584.

91 Moran NR, Webster B, Lee KM, et al. Epstein Barr virus-positive mucocutaneous ulcer of the colon associated Hodgkin lymphoma in Crohn's disease. World J Gastroenterol. 2015; 21 : 6072-6076.

92 Hashimoto K, Nagao T, Saito T, Kinoshita H. Methotrexateassociated lymphoproliferative disorders of the tongue developing in patients with rheumatoid arthritis: a report of 2 cases and a review. Oral Surg Oral Med Oral Pathol Oral Radiol. 2015; 119 : e1-e5

93 Nakauyaca A, Kalro A, Donaldson E, Patel H. Fatal outcome of an Epstein-Barr virus positive mucocutaneous ulcer secondary to methotrexate. Intern Med J. 2016; $46: 1226-1228$.

94 Chen BJ, Fang CL, Chuang SS. Epstein-Barr virus-positive mucocutaneous ulcer. Kaohsiung J Med Sci. 2017; 33 : 50-51.

95 Furudate K, Satake A, Narita N, Kobayashi W. Methotrexaterelated lymphoproliferative disorder in patients with osteonecrosis of the jaw: A 3-case report and literature review. J Oral Maxillofac Surg. 2018; 76 : 97-111.

96 Daroontum T, Kohno K, Eladl AE, et al. Comparison of Epstein-Barr virus-positive mucocutaneous ulcer associated with treated lymphoma or methotrexate in Japan. Histopathology. 2018; 72 : 1115-1127.
97 Satou A, Banno S, Hanamura I, et al. EBV-positive mucocutaneous ulcer arising in rheumatoid arthritis patients treated with methotrexate: Single center series of nine cases. Pathol Int. $2019 ; 69: 21-28$

98 Daroontum T, Kohno K, Inaguma Y, et al. Epstein-Barr virus (EBV)-positive diffuse large B-cell lymphoma arising in patient with a history of EBV-positive mucocutaneous ulcer and EBVpositive nodal polymorphous B-lymphoproliferative disorder. Pathol Int. 2019; 69 : 37-41

99 Clarke LE, Junkins-Hopkins J, Seykora JT, Adler DJ, Elenitsas R. Methotrexate-associated lymphoproliferative disorder in a patient with rheumatoid arthritis presenting in the skin. J Am Acad Dermatol. 2007; 56 : 686-690.

100 Tanaka A, Shigematsu H, Kojima M, Sakashita H, Kusama K. Methotrexate-associated lymphoproliferative disorder arising in a patient with adult Still's disease. J Oral Maxillofac Surg. 2008; 66 : 1492-1495.

101 Roberts TK, Chen X, Liao JJ. Diagnostic and therapeutic challenges of EBV-positive mucocutaneous ulcer: a case report and systematic review of the literature. Exp Hematol Oncol. 2016; $5: 13$.

102 Makino Y, Tani C, Miyokawa N, et al. Multiple intestinal ulcers associated with primary Epstein-Barr virus infection in a patient with rheumatoid arthritis undergoing methotrexate therapy. Intern Med. 2015; 54 : 2851-2855.

103 Au JK, Said JW, Sepahdari AR, St. John MA. Head and neck Epstein-Barr virus mucocutaneous ulcer: Case report and literature review. Laryngoscope. 2016; $126:$ 2500-2504.

104 Saleh JZ, Lee LH, Schieke SM, Hosking PR, Hwang ST. Methotrexate-induced $\mathrm{CD} 30^{+} \mathrm{T}$-cell lymphoproliferative disorder of the oral cavity. JAAD Case Rep. 2016; 2 : 354-356.

105 Mishima S, Takahashi K, Tomioka T, Bessho K. Numb chin syndrome as initial manifestation of bisphosphonate-related osteomyelitis of the jaw and methotrexate-associated lymphoproliferative disorders: a rare case. Br J Oral Maxillofac Surg. 2016; 54 : 114-115.

106 Hujoel IA, Rubio-Tapia A, Dao LN, Porrata LF, Kane SV. Epstein-Barr virus-positive mucocutaneous ulcer in an immunosuppressed patient. ACG Case Rep J. 2018; 5 : e32.

107 Lee YM, Kim JM. Epstein-Barr virus-positive mucocutaneous ulcer colliding with extranodal marginal zone lymphoma of mucosa-associated lymphoid tissue (malt lymphoma) that developed in the palatine tonsils of an immunocompetent patient after gastric lymphoma relapse. Blood Res. 2018; 53 : 329-332.

108 McCormack C, Huang Q. EBV ${ }^{+}$mucocutaneous ulcer: a new entity of WHO 2017. Blood. 2018; $131: 1993$.

109 Namiki T, Sone Y, Miura K, Tanaka M, Yokozeki H. Methotrexate-associated lymphoproliferative disorder: Dermoscopic features. Case Rep Dermatol. 2018; 10 : 149-153.

110 Ravi PY, Sigamani E, Jeelani Y, Manipadam MT. Methotrexateassociated Epstein-Barr virus mucocutaneous ulcer: A case report and review of literature. Indian J Pathol Microbiol 2018; $61: 255-257$

111 Schwartz Z, Bowe RB, Coleman M, Magro CM. Pediatric oral Epstein-Barr virus associated self-remitting CD30+ 
lymphoproliferative disorder: A distinct entity. Ann Diagn Pathol. 2018; 37 : 57-61.

112 Sinit RB, Horan KL, Dorer RK, Aboulafia DM. Epstein-Barr virus-positive mucocutaneous ulcer: Case report and review of the first 100 published cases. Clin Lymphoma Myeloma Leuk. 2019; 19 : e81-e92.

113 Kojima M, Motoori T, Hosomura Y, et al. Atypical lymphoplasmacytic and immunoblastic proliferation from rheumatoid arthritis: A case report. Pathol Res Pract. 2006; 202 : 51-54.

114 Nagai S, Izutsu K, Watanabe T, Kurokawa M. Simultaneous appearance of methotrexate-associated lymphoproliferative disorder and tuberculous meningitis demonstrating the definitive role of immunosuppression. Ann Hematol. 2009; 88 : 589-590

115 Joannides AJ, El-Shaboury H, Guirguis R, Fasler JJ, Rajagopal V. Methotrexate-associated lymphoproliferative disorder presenting as disseminated malignancy. Rheumatology. (Oxford) 2011; $50: 1927-1928$.

116 Fujita T, Tanabe M, Iida E, Okimoto T, Matsunaga N. Multimodality imaging findings of methotrexate-related EpsteinBarr virus-associated hepatic tumor. Clin Imaging. 2013; 37 : 962-964.

117 Fukushima M, Katayama Y, Yokose N, et al. Primary central nervous system malignant lymphoma in a patient with rheumatoid arthritis receiving low-dose methotrexate treatment. Br J Neurosurg. 2013; $27: 824-826$.

118 Suemori K, Hasegawa H, Ishizaki J, et al. Methotrexateassociated lymphoproliferative disease with multiple pulmonary nodules in a patient with rheumatoid arthritis. Intern Med. 2015; $54: 1421-1425$.

119 Katsoulas N, Chrysomali E, Piperi E, Levidou G, SklavounouAndrikopoulou A. Atypical methotrexate ulcerative stomatitis with features of lymphoproliferative like disorder: Report of a rare ciprofloxacin-induced case and review of the literature. J Clin Exp Dent. 2016; 8 : e629-e633.

120 Nakamura H, Shibata Y, Takeda T. Sternoclavicular joint swelling in a patient with rheumatoid arthritis. J Rheumatol. 2016; 43 : 2074-2075.

121 Kobayashi Y, Kimura K, Fujitsu Y, et al. Methotrexateassociated orbital lymphoproliferative disorder in a patient with rheumatoid arthritis: a case report. Jpn J Ophthalmol. 2016; $60: 212-218$.

122 Furukawa S, Oobu K, Moriyama M, et al. Oral methotrexaterelated lymphoproliferative disease presenting with severe osteonecrosis of the jaw: A case report and literature review. Intern Med. 2018; 57 : 575-581.

123 Lai WF, Chin YP, Liu CW, Tsai CY. Methotrexate-associated lymphoproliferative disease with multiple pulmonary nodules in a patient with rheumatoid arthritis. BMJ Case Rep. 2017; 2017.

124 Sato N, Toide N, Kizawa M, et al. Methotrexate-associated lymphoproliferative disorder in a patient with neuromyelitis optica spectrum disorder: An implication for pathogenesis mediated by Epstein-Barr virus. J Neurol Sci. 2017; 379 : 219-221.

125 Hashimoto K, Akagi M. Lymphoproliferative disorder in an elderly rheumatoid arthritis patient after longterm oral methotrexate administration: A case report. Mol Clin Oncol. 2018; $9:$ 293-296.

126 Tokuhira M, Tabayashi T, Tanaka Y, et al. The aggressive clinical courses of Hodgkin lymphoma primarily diagnosed as methotrexate-induced non-specific lymphoproliferative disorder in patients with rheumatoid arthritis. J Clin Exp Hematop. 2017; $56: 165-169$.

127 Baird RD, van Zyl-Smit RN, Dilke T, Scott SE, Rassam SMB. Spontaneous remission of low-grade B-cell non-Hodgkin's lymphoma following withdrawal of methotrexate in a patient with rheumatoid arthritis: case report and review of the literature. Br J Haematol. 2002; 118 : 567-568.

128 Hoshida Y, Tomita Y, Zhiming D, et al. Lymphoproliferative disorders in autoimmune diseases in Japan: analysis of clinicopathological features and Epstein-Barr virus infection. Int J Cancer. 2004; $108:$ 443-449.

129 Ishigaki S, Masaoka T, Kameyama H, et al. Methotrexateassociated lymphoproliferative disorder of the stomach presumed to be mucosa-associated lymphoid tissue lymphoma. Intern Med. 2018; 57 : 3249-3254.

130 Katsuragi T, Iwashige A, Tsukada J. [Immunodeficiencyassociated Burkitt lymphoma developed in a patient receiving a long-term methotrexate therapy for rheumatoid arthritis]. Rinsho Ketsueki. 2016; 57 : 9-14.

131 Kikuchi J, Kaneko Y, Kasahara H, et al. Methotrexateassociated intravascular large B-cell lymphoma in a patient with rheumatoid arthritis. Intern Med. 2016; 55 : 1661-1665.

132 Hagihara M, Mese T, Ohara S, et al. Methotrexate-associated intravascular large B-cell lymphoma in a patient with rheumatoid arthritis: A very rare case. Intern Med. 2018; 57 : 3001-3005.

133 Takajo I, Umekita K, Ikei Y, Oshima K, Okayama A. Adult T-cell leukemia/lymphoma as a methotrexate-associated lymphoproliferative disorder in a patient with rheumatoid arthritis. Intern Med. 2018; 57 : 2071-2075.

134 Hatanaka K, Nakamura N, Kojima M, et al. Methotrexateassociated lymphoproliferative disorders mimicking angioimmunoblastic T-cell lymphoma. Pathol Res Pract. 2010; 206 : 9-13.

135 Kiyasu J, Arakawa F, Haji S, et al. Methotrexate-associated lymphoproliferative disorders with angioimmunoblastic T-cell lymphoma-like features accompanied by gamma-heavy chain disease in a patient with rheumatoid arthritis. Pathol Int. 2018; 68 : 485-490; Epub ahead of print.

136 Singh BK, Antony PT, Verma SK, Basu D, Negi VS. Anaplastic large cell lymphoma in a patient with systemic onset juvenile arthritis: case report and review of literature. Int J Rheum Dis. 2014; 17 : 573-577.

137 Cornejo CM, Novoa RA, Krisch RE, Kim EJ. Low-dose radiotherapy for primary cutaneous anaplastic large-cell lymphoma while on low-dose methotrexate. Cutis. 2016; 98 : 253-256.

138 Nemoto Y, Taniguchi A, Kamioka M, et al. Epstein-Barr virusinfected subcutaneous panniculitis-like T-cell lymphoma associated with methotrexate treatment. Int J Hematol. 2010; 92 : 364-368.

139 Hatachi S, Kunitomi A, Aozasa K, Yagita M. CD8 ${ }^{+}$T-cell lymphoproliferative disorder associated with Epstein-Barr virus in 
a patient with rheumatoid arthritis during methotrexate therapy. Mod Rheumatol. 2010; 20 : 500-505.

140 Koji H, Yazawa T, Nakabayashi K, et al. CD8-positive T-cell lymphoproliferative disorder associated with Epstein-Barr virus-infected B-cells in a rheumatoid arthritis patient under methotrexate treatment. Mod Rheumatol. 2016; 26 : 271-275.

141 Kamiya Y, Toyoshima M, Suda T. Endobronchial involvement in methotrexate-associated lymphoproliferative disease. Am J Respir Crit Care Med. 2016; 193 : 1304-1306.

142 Terroso G, Aleixo J, Bernardes M, et al. Nasal type extranodal NK/T cell lymphoma diagnosed in a patient with rheumatoid arthritis under methotrexate. Acta Reumatol Port. 2014; 39 : 77-81.

143 Tajima S, Takanashi Y, Koda K, Fukayama M. Methotrexateassociated lymphoproliferative disorder presenting as extranodal NK/T-cell lymphoma arising in the lungs. Pathol Int. 2015; $65: 661-665$.

144 Uchida T, Inoue M, Hua J, et al. Iatrogenic immunodeficiencyassociated Epstein-Barr virus (EBV) -negative natural killer cell lymphoproliferative disorder in a patient undergoing rheumatoid arthritis therapy. Rinsho Ketsueki. 2017; 58 : 624-629.

145 Sliesoraitis S, Khan R, Rothman J. Methotrexate-induced Hodgkin disease in a patient with systemic lupus erythematosus. J Am Osteopath Assoc. 2009; 109 : 325-328.

146 Dong L, Chen Y, Masaki Y, Okazaki T, Umehara H. Possible mechanisms of lymphoma development in Sjogren's syndrome. Curr Immunol Rev. 2013; 9 : 13-22.

147 Tarella C, Gueli A, Ruella M, Cignetti A. Lymphocyte transformation and autoimmune disorders. Autoimmun Rev. 2013; $12: 802-813$.

148 Lam GY, Halloran BP, Peters AC, Fedorak RN. Lymphoproliferative disorders in inflammatory bowel disease patients on immunosuppression: lessons from other inflammatory disorders. World J Gastrointest Pathophysiol. 2015; 6 : 181-192.

149 Pereira VPL, Robazzi TCMV. Biological therapy and development of neoplastic disease in patients with juvenile rheumatic disease: a systematic review. Rev Bras Reumatol Engl Ed. 2017; 57 : 174-181.

150 Smedby KE, Ponzoni M. The aetiology of B-cell lymphoid malignancies with a focus on chronic inflammation and infections. J Intern Med. 2017; $282:$ 360-370.

151 Yang C, Huang J, Huang X, et al. Risk of lymphoma in patients with inflammatory bowel disease treated with antitumour necrosis factor alpha agents: A systematic review and meta-analysis. J Crohns Colitis. 2018; [Epub ahead of print].

152 Romão VC, Talarico R, Scirè CA, et al. Sjögren's syndrome: state of the art on clinical practice guidelines. RMD Open. 2018; 4(suppl 1): e000789.

153 Klein A, Polliack A, Gafter-Gvili A. Systemic lupus erythematosus and lymphoma: Incidence, pathogenesis and biology. Leuk Res. 2018; 75 : 45-49.

154 Lelièvre JD, Sacre K, Adle-Biassette H, et al. Epstein-Barr virus-associated lymphoproliferative disease after long-standing cyclosporine therapy for psoriasis: A case of spontaneous regression. J Am Acad Dermatol. 2005; 52(suppl 1): S24-S27.

155 Dubey S, Adebajo AO. Lymphoproliferative disorder due to sulphasalazine. BMJ Case Rep. 2009; 2009.

156 Ikeda T, Toyama S, Ogasawara M, et al. Rheumatoid arthritis complicated with immunodeficiency-associated lymphoproliferative disorders during treatment with adalimumab. Mod Rheumatol. 2012; 22 : 458-462.

157 McGinness JL, Spicknall KE, Mutasim DF. Azathioprineinduced EBV-positive mucocutaneous ulcer. J Cutan Pathol. 2012; $39: 377-381$

158 Oda K, Minata M. Drug free remission after steroid-dependent disappearance of lymphoproliferative disorder in rheumatoid arthritis patient treated with TNF-alpha blockade: case study. Springerplus. 2015; $4: 41$.

159 Nosotti L, Baiocchini A, Bonifati C, et al. Unusual case of B cell lymphoma after immunosuppressive treatment for psoriasis. World J Hepatol. 2015; 7 : 814-818.

160 D'Haens G, Reinisch W, Colombel JF, et al.; ENCORE investigators. Five-year safety data from ENCORE, a European observational safety registry for adults with Crohn's disease treated with infliximab [Remicade(R)] or conventional therapy. J Crohns Colitis. 2017; $11:$ 680-689.

161 Okada K, Asakura S, Yano T, Kishimoto T. EBV-positive PELlike lymphoma that developed in the course of antisynthetase syndrome treated with tacrolimus. Int J Hematol. 2018; 108 : 329-334.

162 Tokuhira M, Saito S, Suzuki K, et al. Clinicopathological features of clinical methotrexate-related lymphoproliferative disorders. Leuk Lymphoma. 2019; $5: 1-8$.

163 Singh JA, Saag KG, Bridges SL Jr, et al. 2015 American college of rheumatology guideline for the treatment of rheumatoid arthritis. Arthritis Rheumatol. 2016; $68: 1-26$.

164 https://www.ryumachi-jp.com/publication/pdf/MTX2016kanni. pdf.

165 Kameda H, Fujii T, Nakajima A, et al. Japan college of rheumatology guideline for the use of methotrexate in patients with rheumastoid arthritis. Mod Rheumatol. 2018; 24 : 1-10.

166 Stevens SJC, Verschuuren EA, Pronk I, et al. Frequent monitoring of Epstein-Barr virus DNA load in unfractionated whole blood is essential for early detection of posttransplant lymphoproliferative disease in high-risk patients. Blood. 2001; 97 : 1165-1171.

167 Wagner HJ, Wessel M, Jabs W, et al. Patients at risk for development of posttransplant lymphoproliferative disorder: plasma versus peripheral blood mononuclear cells as material for quantification of Epstein-Barr viral load by using real-time quantitative polymerase chain reaction. Transplantation. 2001; $72: 1012-1019$.

168 Tsai DE, Douglas L, Andreadis C, et al. EBV PCR in the diagnosis and monitoring of posttransplant lymphoproliferative disorder: results of a two-arm prospective trial. Am J Transplant. 2008; 8 : 1016-1024.

169 Luskin MR, Heil DS, Tan KS, et al. The impact of EBV status on characteristics and outcomes of posttransplantation lymphoproliferative disorder. Am J Transplant. 2015; 15 : 2665-2673.

170 Tosato G, Steinberg AD, Blaese RM. Defective EBV-specific suppressor T-cell function in rheumatoid arthritis. N Engl J Med. 1981; $305:$ 1238-1243. 
171 Toussirot E, Wendling D, Tiberghien P, Luka J, Roudier J. Decreased $\mathrm{T}$ cell precursor frequencies to Epstein-Barr virus glycoprotein gp110 in peripheral blood correlate with disease activity and severity in patients with rheumatoid arthritis. Ann Rheum Dis. 2000; 59 : 533-538.

172 Balandraud N, Meynard JB, Auger I, et al. Epstein-Barr virus load in the peripheral blood of patients with rheumatoid arthritis: accurate quantification using real-time polymerase chain reaction. Arthritis Rheum. 2003; 48 : 1223-1228.

173 Feng WH, Cohen JI, Fischer S, et al. Reactivation of latent Epstein-Barr virus by methotrexate: a potential contributor to methotrexate-associated lymphomas. J Natl Cancer Inst. 2004; $96: 1691-1702$.

174 Balandraud N, Roudier J. Epstein-Barr virus and rheumatoid arthritis. Joint Bone Spine. 2018; 85 : 165-170.

175 Kuusela E, Kouri VP, Olkkonen J, et al. Serum Epstein-Barr virus DNA, detected by droplet digital PCR, correlates with disease activity in patients with rheumatoid arthritis. Clin Exp Rheumatol. 2018; 36 : 778-784.
176 Kawada J, Iwata N, Kitagawa Y, Kimura H, Ito Y. Prospective monitoring of Epstein-Barr virus and other herpesviruses in patients with juvenile idiopathic arthritis treated with methotrexate and tocilizumab. Mod Rheumatol. 2012; 22 : 565-570.

177 Miceli-Richard C, Gestermann N, Amiel C, et al. Effect of methotrexate and anti-TNF on Epstein-Barr virus T-cell response and viral load in patients with rheumatoid arthritis or spondylarthropathies. Arthritis Res Ther. 2009; 11 : R77.

178 Balandraud N, Texier G, Massy E, et al. Long term treatment with abatacept or tocilizumab does not increase Epstein-Barr virus load in patients with rheumatoid arthritis - A three years retrospective study. PLoS One. 2017; 12 : e0171623.

179 Fujieda M, Tsuruga K, Sato T, et al. Monitoring of EpsteinBarr virus load and killer T cells in patients with juvenile idiopathic arthritis treated with methotrexate or tocilizumab. Mod Rheumatol. 2017; 27 : 66-71. 